\title{
Market Maker Inventories and Stock Prices
}

\author{
Terrence Hendershott \\ U.C. Berkeley
}

\author{
Mark S. Seasholes \\ U.C. Berkeley
}

This Version March 3, 2006*

\begin{abstract}
This paper examines daily inventory/asset price dynamics using 11 years of NYSE specialist data. The unique length and breadth of our sample enables the first longer horizon testing of market making inventory models - e.g., Grossman and Miller (1988). We confirm such models' predictions that specialists' positions are negatively correlated with past price changes and positively correlated with subsequent changes. A portfolio that is long stocks with the highest inventory positions and short stocks with the lowest inventory positions has returns of $0.10 \%$ and $0.33 \%$ over the following 1 and 5 days, respectively. These findings empirically validate the causal mechanism - liquidity supplier inventory - that underlies models linking liquidity provision and asset prices. Inventories complement past returns when predicting return reversals. A portfolio long high-inventory/low-return stocks and short low-inventory/high-return stocks yields $1.05 \%$ over the following 5 days. Order imbalances calculated from signing trades relative to quotes also predict reversals and are complementary to inventories and past returns. Finally, specialist inventories can be used to predict return continuations over a one-day horizon.
\end{abstract}

Keywords: Market Maker, Inventory, Liquidity Provision

JEL number: G12 G14

\footnotetext{
${ }^{*}$ We thank the New York Stock Exchange for providing data-especially Katharine Ross and Jennifer Chan. We thank Larry Glosten, Charles Jones, Rich Lyons, and Christine Parlour for helpful comments. Hendershott gratefully acknowledges support from the National Science Foundation. Part of this research was conducted while Hendershott was the visiting economist at the New York Stock Exchange. Contact information: Mark S. Seasholes, U.C. Berkeley-Haas School, 545 Student Services Bldg., Berkeley CA 94720-1900; Tel: 510-642-3421; Fax: 510-6424700; email: mss@haas.berkeley.edu.
} 


\section{Introduction}

Empirical studies linking liquidity provision to asset prices follow naturally from inventory models. Liquidity suppliers and market markers profit from providing immediacy to less patient investors but have limited inventory carrying and risk bearing capacity. Similarly, limits to arbitrage arguments rely on the idea that certain market participants accommodate buying or selling pressure. These liquidity suppliers/arbitrageurs only bear the risk of holding undiversified positions if they are compensated by favorable subsequent price movements. Thus, when inventories are large, liquidity suppliers have taken on risk and prices should subsequently reverse. ${ }^{1}$

By identifying and studying the inventories of traders who are central to the trading process and whose primary roll is to provide liquidity - NYSE specialists - over an 11-year period this paper contributes to a deeper understanding of inventory/asset price dynamics. To focus on the longer horizons impacts of inventory we use daily inventory measures and eliminate bid-ask bounce by calculating returns using quote midpoints. The length of our sample enables us to confirm the underlying causal mechanism - liquidity supplier inventory-behind attempts to link liquidity and stock returns through return reversals. Prior data on inventories typically cover relatively short periods of time and/or a limited number of securities. While these limitations prevented testing for the inventory/price relationships at interday horizons, the microstructure literature has been quite successful in showing that order flow and inventories play an important role in intraday trading and price formation. ${ }^{2}$

This paper examines the relationship between closing market maker (specialist) inventories and future stock prices at daily and weekly horizons. We find that specialist inventories are negatively correlated with contemporaneous returns at both the aggregate market and individual stock levels. This is consistent with specialists acting as dealers and temporarily accommodating buying and selling pressure. For the specialist to be compensated for taking

\footnotetext{
${ }^{1}$ Reversals can occur over intraday horizons due to market makers buying at the bid and selling at the ask, e.g., Amihud and Mendelson (1980), Ho and Stoll (1981), and Roll (1984). Over longer horizons, liquidity provider takes positions and risk, e.g., Grossman and Miller (1988) and Spiegel and Subrahmanyam (1995), that lead to reversals. These longer-term inventory-induced reversals are empirically similar to, but on a larger and market-wide scale than reversals following block trades-Kraus and Stoll (1978).

${ }^{2}$ For examples using NYSE specialist data see Hasbrouck and Sofianos (1993), Madhavan and Smidt (1993), and Madhavan and Sofianos (1998). For examples using London Stock Exchange market maker data see Hansch, Naik, and Viswanathan (1998), Reiss and Werner (1998), and Naik and Yadav (2003). For futures markets data see Mann and Manaster (1996). For options market data see Garleanu, Pedersen, and Poteshman (2005). For foreign exchange data see Lyons (2001) and Cao, Evans, and Lyons (2006).
} 
on inventory, he must unwind positions at better prices than those prices at which the position was accumulated. Using returns calculated with quotes (to avoid bid-ask bounce), we find that a value-weighted portfolio of stocks where the specialist is long outperforms a portfolio of stocks where the specialist is short by 10.25 basis points the next day (9.96 basis points risk-adjusted). ${ }^{3}$ The second day following portfolio formation, the return is 10.15 basis points. Returns decline steadily to 3.43 basis points at day five. All these returns are statistically significant. At day ten, the long-short portfolio return is down to two basis points and is no longer statistically significant. The cumulative return of the long-short portfolio is 41.12 basis points over 10 days. While these returns seem large, specialists do not disclose their inventory positions. Predictability based on inventories comes from non-public information.

Because inventory data have previously been unavailable to study longer-horizon returns, researchers have constructed clever proxies for market-maker inventories and limited risk bearing capacity. Proxies such as order imbalances and "liquidity shocks" capture the demand for liquidity, which the suppliers of liquidity presumably accommodate. Campbell, Grossman, and Wang (1993) examine how trading volume interacts with past returns in determining future return reversals. Pastor and Stambaugh (2003) use a related measure to show that liquidity is a priced risk factor. Chordia, Roll, and Subrahmanyam (2002) study how market-wide order imbalances - buy orders less sell orders - predict reversals of market returns. ${ }^{4}$ Simple return reversals in individual stocks - Lehmann (1990) and others - may also be related to inventory effects. Our approach of directly measuring a supply of available liquidity (i.e., inventories) is complementary to these studies. This paper broadens our understanding of the complex and dynamic process of demanding and supplying liquidity by studying it from the liquidity-supplier side.

\footnotetext{
${ }^{3}$ The price reversals are also consistent with inventory models where a market maker uses his quotes to attract order flow on one side of the market to reduce his inventory position. For example, if other investors have been buying from the specialist, prices have been rising and the specialist has a short position; the specialist then raises his quotes to the point where investors begin to sell and this selling leads to prices subsequently falling.

${ }^{4}$ Order imbalances are easily interpretable if all trades occur with a market maker. The NYSE up-tick rule for short-sales effectively requires all short sellers to use limit orders. This can result in misclassification of these trades. Diether, Lee, and Warner (2005) provide evidence showing how the uptick rule causes order imbalances to be positive on average. The authors also show how Regulation SHO's 2005 relaxation of the up-tick rule largely eliminates the positive bias in NYSE order imbalances that are signed using the Lee and Ready (1991) algorithm. Given that Boehmer, Jones, and Zhang (2005) and Diether, Lee, and Warner (2005) show that shorting selling is between 13 and $25 \%$ of NYSE volume and Boehmer, Jones, and Zhang (2005) show that short selling contains information about future price movements, this misclassification of short selling is of significant potential concern. We discuss this and related issues further in Sections 5 and 6 .
} 
To examine the relationship between inventory reversals and simple return-reversals, we repeat our daily sort procedure using returns. Sorting on today's price change yields no evidence of return reversals the next day. However, at 5-day horizons we find the usual significant return reversals of 59 basis points. The return and inventory measures compliment each other. A double sort of past returns and inventories shows that the return reversals at 5 days are roughly twice as large in stocks where inventories are large. The 5-day return of a portfolio long high-inventory/low-return stocks and short low-inventory/high-return stocks is 105 basis points.

Order imbalances - the difference between buyer-initiated and seller-initiated trading volume as determined by the transaction prices and quotes - are positively correlated with contemporaneous returns - as in Chordia and Subrahmanyam (2004). Order imbalances are negatively correlated with inventories and changes in inventories. Order imbalances do not predict return reversals the next day, but do predict reversals of 32 basis points over the next 5 days. A double sort of past order imbalances and inventories gives a 5-day return of 55 basis points on a portfolio long high-inventory/low-order-imbalance stocks and short low-inventory/high-order-imbalance stocks.

To attempt to disentangle order imbalances, past returns, and inventories we run crosssectional (Fama-MacBeth) regressions. As with single sorts at one-day horizons, the inventory measure is individually significant and past returns are not significant. Unlike the single sorts, order imbalances predict reversals over the next day. All three measures are individually significant at a one-week horizon. When all three measures are combined at a one-week horizon, the inventory and order imbalance measures' significance declines. When predicting returns two weeks ahead, all three variables predict reversals individually with returns being statistically significant, order imbalances being marginally significant, and inventories not being statistically significant. When all three variables are combined, returns predict reversals two weeks ahead while inventories and order imbalances do not.

We find that specialist inventory positions are asymmetric. Specialists take larger long positions when prices fall than short positions when prices rise. Although this is something not found in inventory models, it is consistent with the empirical findings that large buys have a larger price impact than large sells (Kraus and Stoll (1972) and others). The average inventory position is positive and the extreme long positions are several times as large as the extreme short positions. The asymmetry in the long versus short inventory positions also appears in the return reversals. The 10-day return for the long portion of the portfolio where specialist inventories are highest is 18 basis points above the market while the 10- 
day return for the short portion of the portfolio where specialist inventories are lowest is 27 basis points above the market. The highest- and lowest-inventory portfolios also exhibit asymmetry prior to formation day with the highest portfolio falling $1.29 \%$ and the lowest portfolio rising $1.48 \%$. Together these findings suggest that specialists prefer to be long shares because either they or other traders face short sale constraints.

Examining inventories and returns together shows that specialist inventories can forecast next day price continuations as well as reversals. When returns are low today and the specialist is already short shares, returns are low on average tomorrow. Similarly, when returns are high today and the specialist is long shares, returns are high tomorrow. This is the opposite of the reversals that occur when returns are low (high) and the specialist is long (short). ${ }^{5}$ At horizons greater than one day, the specialist inventories do not forecast continuations, but do forecast the size of the reversals. This suggests that the specialist is informed about price movements at one-day horizons, but not necessarily beyond, although we cannot identify whether the specialists are skilled traders independent of their unique position at the NYSE.

The remainder of the paper is organized as follows. Section 2 provides a general description of our data and sample. Section 3 examines the correlation between specialist inventories and past price changes. Section 4 studies the relationship between specialist inventories and future price changes. Section 5 discusses how inventories relate to approaches that infer liquidity demands from signed order flow and past price changes. Section 6 investigates how inventories interact with past returns and order imbalances in predicting future price changes. Section 7 concludes the paper.

\section{Data and Descriptive Statistics}

Several data sets are used to construct our sample of daily specialist inventories and prices from 1994 through 2004. CRSP is used to identify firms (permno), trading volume, market capitalization, stock splits/distributions, closing prices, and transaction returns. The Trades and Quotes (TAQ) database is used to identify the closing quotes (MODE=3 in TAQ). Internal NYSE data from the specialist summary file (SPETS) provide the specialist closing

\footnotetext{
${ }^{5}$ The return continuations are consistent with the Llorente, Michaely, Saar, and Wang (2002) finding that the Campbell, Grossman, and Wang (1993) reversal effect is attenuated by informed trading.
} 
inventories data for each stock each day. ${ }^{6}$ Throughout we simply refer to the specialist inventory at the end of the NYSE trading day as inventory. The TAQ master file (MAST) provides the CUSIP number that corresponds to the symbol in TAQ on each date and is used to match with the NCUSIP in the CRSP data. ${ }^{7}$ We consider only common stocks (SHRCLS $=10$ or 11 in CRSP). This provides a sample of more than four million stock-day observations.

To remove bid-ask bounce, close-to-close returns are calculated using bid-ask quote midpoints. On days when the closing quotes are not in TAQ (0.57\% of the sample) and on days with distributions ( $0.97 \%$ of the sample), we use the CRSP prices/returns. The paper's results are not sensitive to whether or not we discard these observations. We eliminate firms with share price over $\$ 500$ ( $0.17 \%$ of the sample) ${ }^{8}$

We begin by presenting aggregate market inventory levels which are the sum over specialists' closing inventories in each stock. Figure 1 graphs aggregate market inventory levels and the total market capitalization of all stocks in our sample between 1994 and 2004. The aggregate market inventory averages about $\$ 200$ million at the end of each day, but declines somewhat starting in late 2002. The volatility of the inventory levels increases over the beginning of the sample period. As can be seen in the figure, aggregate inventory levels reach a billion dollars (long) and drop below $\$ 200$ million (short).

\section{[ Insert Figure 1 Here ]}

Panel A of Table 1 provides time series statistics on the aggregate inventory. The inventory level fluctuates with a daily standard deviation of $\$ 137$ million and the standard deviation

\footnotetext{
${ }^{6}$ The specialist has informational and last mover advantages over other market participants. He can arguably be considered the marginal liquidity provider in the market. Such advantages make specialist inventories well-suited for studying the price effects of inventory. The specialist also has obligations. The specialist is discouraged from demanding liquidity and the specialist must trade after public limit orders at every price- see Coughenour and Harris (2004). Planned reorganization of the NYSE to increase fully-electronic trading may change the specialist's role. While the proposed plan continues to provide the specialist with a central role in trade - trading algorithmically against incoming order flow - the specialist role could be diminished making it more difficult to identify the marginal liquidity provider.

${ }^{7}$ The symbol in TAQ and ticker in CRSP only match $90 \%$ of time in our CUSIP matched sample, suggesting that using the TAQ master file to obtain CUSIPs is useful.

${ }^{8}$ The high price criteria eliminates Berkshire Hathaway which has quotes and closing prices differing by a factor of 10 on days in the early part of the sample period. The papers' results are also not sensitive to the inclusion of low-priced stocks.
} 
of inventory changes is $\$ 107$ million. Absolute changes in the inventory position average $\$ 77$ million each day with a standard deviation of $\$ 75$ million.

[ Insert Table 1 Here ]

Panel B of Table 1 provides cross-sectional statistics on inventories and inventory changes at the individual stock level on a daily basis. Median inventories are $\$ 41,180$ per stock, which is only $1 \%$ of average daily trading volume. The mean per-stock inventory is $\$ 119$ thousand, which corresponds to $24 \%$ of average daily trading volume. The $1^{\text {st }}$ and $99^{\text {th }}$ percentiles show that specialists occasionally have closing positions more than a million dollars long or short, which represent 1.13 days (4.61) average trading volume for short (long) positions. The positive mean inventory and large extreme long positions indicate that specialists possibly face asymmetric costs of long versus short positions. The most natural explanation is that when specialists are short they need to be a buyer to return their inventory to its desired level, requiring other traders to be sellers. If some traders face short-sale constraints, the specialist can anticipate that unwinding large short positions is more difficult than unwinding large long positions. A related short-sale constraint explanation is that the NYSE up-tick rule effectively forces short sellers to provide liquidity via limit orders. These short-sale limit orders increase competition at the ask-Diether, Lee, and Werner (2005) - potentially making the liquidation of large short positions more costly.

\section{Inventories and Past Returns}

Figure 2 plots past returns and net inventory changes at the market level. As suggested by the changes in Figure 1, aggregate market inventory can move up or down by hundreds of millions of dollars during a given day. The negative slope of the scatter plot indicates that specialists act as dealers and temporarily accommodate buying and selling pressure. The one outlier ( $\$ 849$ million change in inventory and $-3.65 \%$ market return) comes from a day when several specialists accumulate several hundred million dollar short positions in stocks that went up when the rest of the market was falling. Panel A of Table 2 shows that changes in aggregate inventory has a -0.71 correlation with contemporaneous returns. Because inventories typically start the day above or below their average level, the correlation of returns over a day and inventory levels at the end of the day is somewhat lower at -0.57 .

[ Insert Figure 2 Here ] 
Panel B of Table 2 provides the cross-sectional mean of individual stocks' time series correlation between inventory changes and returns. The mean correlation between dollar inventory level and returns is -0.23 . The fact that correlation is closer to zero with individual stock data than with aggregate market data is consistent with noise in individual stock returns (and possibly inventories) that averages out when aggregated. This also suggests that refining our measure of inventory from simple dollar inventory may be beneficial.

[ Insert Table 2 Here ]

Other possible measures of specialist inventory account for the distance from a target inventory level - as in Madhavan and Smidt (1993) — and variations in the riskiness of inventory positions. To allow for a time-varying target inventory level, at each date $t$ we calculate the moving average of each stock's inventory level over the past 3 months beginning 10

days ago, i.e., days $t-11$ to $t$-70, and refer to this as $\mu^{I N V}$. We require 30 days of data to calculate the target inventory level based on the lagged moving average. Subtracting this from the inventory level does not significantly affect the correlation with returns. The same dollar amount of inventory may pose different levels of risk to specialists due to differences in stock volatility, average trading volume, competition for liquidity provision, specialist participation rates, and other factors that are difficult to measure directly. Rather than posit a functional form for the amount of risk per dollar of inventory, we attempt to directly infer it from changes in the specialist's past inventory levels. Inventory levels that historically vary up and down more suggest that specialists are willing to carry more inventory in that stock because they believe larger positions in that stock are less problematic to liquidate. Therefore, we use the standard deviation of past inventory (calculated over the same time period as $\mu^{I N V}$ ) to standardize the current inventory position. We refer to the standardized inventory as $z^{I N V} \equiv \frac{I N V_{t}-\mu^{I N V}}{\sigma^{I N V}}$. This standardized inventory is backward looking version of the standardized inventory measure used by Hansch, Naik, and Viswanathan (1998). The correlation across inventory measures is high with the correlation with returns being slightly more negative for the standardized inventory.

\section{Inventories and Future Returns}

Figure 2 and Table 2 show that, consistent with inventory models, the specialist's inventory at then end of the day is negatively correlated with price changes over that day. We now test 
the other inventory model prediction that inventory levels forecast future return reversals. The reversal prediction is commonly used to justify and examine the relationship between liquidity and prices. Table 3 studies the impact of inventories on subsequent prices. Following the standard sorting and portfolio-formation approach, we sort stocks into quintiles each day of our sample period based on the three inventory measures. Panel A is dollar inventory levels and labeled " $I N V$ "; Panel B uses deviations of inventory from the specialist's target inventory and labeled "INV $-\mu^{I N V " ; ~ P a n e l ~ C ~ u s e s ~ d e v i a t i o n s ~ f r o m ~ t a r g e t ~ i n v e n t o r y ~ s t a n d a r d i z e d ~}$

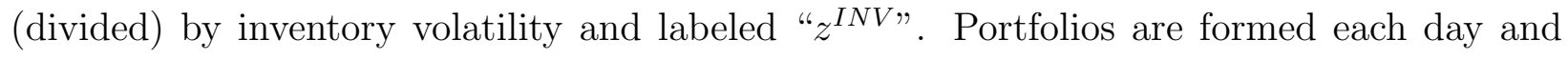
returns are calculated using closing mid-quote returns with market capitalizations as weights. We use mid-quote returns, value weighting, and quintiles to minimize the impact of small illiquid stocks.

\section{[ Insert Table 3 Here ]}

Given the correlation between the three inventory measures, it is not surprising that all sorts put larger values of each inventory measure in the outer quintiles. As in Panel B of Table 1, the highest-inventory positions are roughly twice as positive, and the lowestinventory positions are negative. Sorting by dollar inventory (Panel A) puts the highest turnover, least volatile, and largest market capitalization stocks in the outer quintiles. This suggests that inventory is more manageable in larger, more active stocks, so specialists are willing to take larger positions in those stocks. While this is expected, it leads quintile portfolios to have different stock characteristics. Subtracting the target inventory reduces the market capitalization differences across quintile somewhat. Standardizing by past inventory volatility helps to even out the market capitalization differences across quintiles more. Note that in Panel C, the larger, more active, less volatile stocks appear slightly more frequently in the center quintiles. Given that we are trying to isolate inventory effects from other stock characteristics, we will focus on the standardized inventory measure for the rest of the paper, although the other inventory measures yield similar results.

All three inventory sorts provide qualitatively similar result in terms of predicting returns: the low-inventory portfolios have returns the next day close to or below zero while the highinventory portfolios have returns between 8 and 10 basis points the next day. Therefore, a portfolio long on the highest-inventory stocks and short the lowest-inventory stocks yields between 7.70 and 10.25 basis points the next day. All have t-statistics greater than nine. The raw returns demonstrate that the inventory positions of liquidity providers forecast future prices. The fact that sorting on dollar inventory, where the large, actively traded firms are 
in the outer portfolios, shows reversals indicates that the inventory/reversal effect is present in large stocks as well. Controlling for the market, the Fama-French size factor, the FamaFrench market-to-book factor, and a momentum factor has little effect on the return of the high inventory minus low inventory portfolio.

To quantify the duration of inventory effects on prices, Figure 3 shows the returns net of the market for the 12 days after portfolio formation. The highest-inventory portfolio increases by 5 basis points (over the market) on the first day, four basis points on the second day, and levels off at 18 cumulative basis points thereafter. The next highest-inventory level portfolio (labeled "P4") increases by 3 basis points the first day, increases by 1.5 basis points on day two, increases by approximately 1 basis point a day on days 3 through 8 , and levels off at 10 cumulative basis points thereafter. The middle portfolio ("P3") drifts up somewhat. The second-lowest inventory portfolio ("P2") declines by 2.6 basis points the first day, decreases by 1.3 basis point a day on days 2 through 3 , before it levels off at -8 cumulative basis points thereafter. The lowest-inventory portfolio declines by 5 basis points each of the first 2 days and decreases by approximately 3 basis points a day on days 3 through 6 . Unlike the others, the lowest-inventory portfolio continues to drift after day 6 , declining to a low of -27 cumulative basis points on day 11 . The cumulative 5-day return difference between the long- and short-inventory portfolios is 32.99 basis points and the cumulative 10-day return difference is 41.12 basis points.

\section{[ Insert Figure 3 Here ]}

The asymmetry between the returns on the highest and lowest portfolios suggests that the specialist's willingness to take larger long positions than short positions translates into differences in future prices. The largest positive positions lead to less mean reversion than the most negative positions. The difference in returns between the highest-inventory and $2^{\text {nd }}$ highest-inventory position is also smaller than the difference in returns between the lowestinventory and $2^{\text {nd }}$ lowest-inventory position. When the specialist is short, other traders must sell for the specialist to reduce his position (buy back shares). Traders who do not already own the stock face short-sale constraints, potentially limiting the number of sellers. In addition, the NYSE up-tick rule effectively requires short sellers to provide liquidity via limit orders. Short-sale limit orders increase competition at the ask, potentially making the liquidation of large short positions more costly. Specialists often give a different explanation for the long-short asymmetry: that they are more sensitive to preventing downward stock price movements and, therefore, take large long positions when others investors are net sellers. 
Given that there is little long-short asymmetry in the changes in inventory in Panel B of Table 1, this latter explanation seems unlikely because the asymmetry appears in inventory levels, but not in changes in inventory.

Long (short) inventories resulting from negative (positive) returns and causing positive (negative) returns the next day is consistent with inventory and liquidity provision models. To examine the pre- and post-formation price changes, Figure 4 extends the returns in Figure 3 back six days in time by adding the portfolio formation day as well as the prior five days. Note that reversals in returns switch the ordering of the high- and low-inventory portfolios. The highest-inventory portfolio is on top in Figure 3, while the highest-inventory portfolio is on the bottom in Figure 4. The middle-quintile portfolio remains close to zero over the entire time. The $2^{\text {nd }}$ highest portfolio based on day 0 inventory declines about 7 basis points a day the three days prior to formation, drops 30 basis points on formation day for a total decrease of 50 basis points, and reverses by 10 basis points as described above. The graphs are consistent with the specialists acquiring their positions as they accommodate the liquidity demands of other traders. The specialists then unwind their positions as prices reverse.

\section{[ Insert Figure 4 Here ]}

The highest- and lowest-inventory portfolios exhibit asymmetry prior to formation day with the high-inventory portfolio falling $1.29 \%$ and the lowest portfolio rising $1.48 \%$. The highest portfolio then reverses 17 basis points over 6 days while lowest portfolio reverses 28 basis points and takes about a week longer to level off. The pre- and post-formation returns show that price changes prior to portfolio formation are many times larger than the reversal. Just as the asymmetry between the sizes and post-formation returns of the longest- and shortest-inventory positions (Table 1) do not naturally arise in inventory models, neither do the asymmetric price movements in the pre-formation periods. The asymmetry in long and short inventory size and pre- and post-formation returns all point to the specialist preferring long positions to short positions. This preference leads to smaller downward price changes and smaller subsequent return reversals.

While the return difference of the outer-quintile portfolios are significant, in Table 4 we test that these are not due to risk by performing the standard procedure of regressing the returns of the long-short portfolio on the market and Fama-French factors. We use post-formation returns for days $t+1, t+2, t+3, t+4, t+5$, and $t+10$. The long-short portfolio loads positively on the market on most dates and positively on the momentum factor on the first days, but 
the alphas in these regressions do not differ noticeably from the simple differences in raw returns. Each of the first 5 days' risk-adjusted return (alpha) is significant. Day 10's alpha remains positive at 2.07 basis points, but the t-statistic is only 1.83 .

[ Insert Table 4 Here ]

To examine the pre- and post-formation inventories Figure 5 provides the standardized inventory levels corresponding to the returns in Figure 4. As with the returns, most of the pre-formation change in inventories occurs on the portfolio formation day with the largest long and short portfolios having standardized inventory levels of about $+/-1.8$. Inventory levels on day $t+1$ are quite similar to those at day $t$-1, showing that inventories exhibit large mean reversion over relatively short horizons. Comparing Figures 4 and 5 shows that the price effects and mean reversion in inventories move together, although the relationship is not strictly linear. While our results show that the marginal additional inventory taken on appears profitable, most of the large long (short) inventory positions occur on days when prices fall (rise). Prices then show small mean reversion relative to the pre-formation return, making these large inventory positions appear unprofitable overall for the specialist. This is consistent with the Hasbrouck and Sofianos (1993) and Coughenour and Harris (2004) evidence that the specialists make most of their money at short horizons and are not profitable at longer horizons.

\section{[ Insert Figure 5 Here ]}

Finally, we briefly examine day of the week effects in the inventory induced reversals. Forming inventory portfolios on Wednesday and calculating weekly returns from Wednesday to Wednesday gives a return of 28.5 basis points on the high inventory minus low inventory portfolio (results not shown in any table.) Forming inventory portfolios at the end of the trading week and calculating returns from then until the end of the subsequent trading week gives a return of 44.4 basis points on the high-inventory minus low-inventory portfolio (results also not shown.) At the end of the trading week the specialists bear the risk of holding their inventory over the weekend. The stronger desire to be flat over the weekend results in inventory positions more strongly predicting future returns. 


\section{Inventories and Measures of Liquidity Demand}

Linking liquidity provision and stock price movement is firmly grounded in models with liquidity supplier inventories and/or limited arbitrageur risk-bearing capacity. Empirical investigations are challenging because the liquidity suppliers and arbitrageurs are typically not identified in data. Therefore, researchers construct proxies for potential liquidity supply based on measures of the demand for liquidity. Such measures include order imbalances and "liquidity shocks." If all trading takes place with a market maker, order imbalances accumulate into inventory.

Chordia, Roll, and Subrahmanyam (2002) extend the short-run microstructure idea of order imbalances - roughly categorizing the amount of trading above the quote midpoint price as buying and categorizing the amount of trading below the quote midpoint as selling with the net of these two being the imbalance - to the daily horizon. They show that daily order imbalances (aggregated across stocks) are positively correlated with the contemporaneous market returns. Imbalances are negatively correlated with the subsequent day's market return, although the correlation with the subsequent day's market return is only statistically significant for negative imbalance days. These return reversals are generally consistent with inventory models and our results. Compared to our direct measure of specialist inventories, using order imbalances has the advantage of potentially measuring liquidity supplied by market participants other than the NYSE specialist. ${ }^{9}$

Chordia and Subrahmanyam (2004) show that order imbalances for individual stocks are positively autocorrelated as are market-wide imbalances. Positive autocorrelation in order imbalances can not easily be accommodated by market makers who have limited risk bearing capacity and want to mean revert their inventories to a desired level. Chordia, Roll, and Subrahmanyam (2005) address this by pointing out that order imbalances are positively correlated with contemporaneous price changes and are also highly persistent from day to day. However, daily returns for NYSE stocks are not serially dependent. They reconcile positive imbalance autocorrelation, positive order imbalance correlation with contemporaneous returns, and no return autocorrelation by showing that after imbalances occur sufficient countervailing trades arrive within the day to remove any daily serial dependence in returns.

\footnotetext{
${ }^{9}$ Diether, Lee, and Warner (2005) show how the NYSE up-tick rule for short selling causes order imbalances to be positive on average using the Lee and Ready (1991) algorithm. Diether, Lee, and Warner (2005) and Boehmer, Jones, and Zhang (2005) show that short selling is between 13 and 25\% of NYSE volume and that short selling predicts future price changes. These findings suggest that using aggregate signed (using only quotes and trades) order imbalance data for individual stocks is potentially problematic.
} 
This illustrates that some complex and subtle dynamics in the trading process are at work and suggests it may be difficult to measure inventories by accumulating order imbalances.

The need to infer from the data when liquidity is being demanded can be avoided by finding traders whose motives are known and whose positions data are available. Coval and Stafford (2005) do this by using mutual fund outflows and inflows. Andrade, Seasholes, and Chang (2005) identify a large group individual investors whose trades cause return reversals at daily, weekly, and monthly frequencies. Campbell, Ramadorai, and Vuolteenaho (2005) use 13-F filings and TAQ data to identify institutional trading. Barber, Odean, and Zhu (2005) use trading activity by trade size to identify noise traders. These papers provide evidence about the compensation required to provide liquidity. However, these papers' results rest on their identification strategy and it is difficult to know how their results generalize. Garleanu, Pedersen, and Poteshman (2005) is perhaps the closest paper to this one in terms of the completeness and precision of the data. They use two sources of data on open interest positions in options to measure the position of options market makers from 1996 to 2001. They show that end-customer demand impacts option prices and can explain a number of option pricing puzzles.

\subsection{Reversals}

When studying reversals, a goal of researchers is to identify stocks, indexed by $i$, that are trading at prices $p_{t}^{i}$ different from their fundamental values $v_{t}^{i}$. Once stocks with large deviations from fundamentals (labeled $\epsilon_{t}^{i}=p_{t}^{i}-v_{t}^{i}$ ) have been identified, the stocks should (eventually) revert back to their fundamental values. ${ }^{10}$ If different stocks revert to their fundamental values at different rates it may be useful to normalize deviations:

$$
\frac{p_{t}^{i}-v_{t}^{i}}{\sigma_{\epsilon_{t}^{i}}}
$$

To implement empirical studies of reversals, researchers have approached Equation (1) from two different directions. The first approach centers on prices and returns; the second on trading imbalances.

\footnotetext{
${ }^{10}$ This example considers log stock prices, denoted by lower case letters, and constant fundamental values. Similar logic applies to examples that consider prices in levels and/or time-varying fundamental values.
} 


\subsection{Prices, Returns, and Reversals}

Estimating a stock's fundamental value, $v_{t}^{i}$, is fraught with difficulties. There is little consensus about the correct valuation model to use. Thus, any tests are subject to dual-hypothesis testing problems. Also, financial data are released quarterly in the United States. This makes studies at higher (daily or weekly) frequencies impractical.

To get around problems associated with estimating $v_{t}^{i}$, researchers typically make two assumptions (implicitly or explicitly). They assume that prices were equal to fundamental values $k$-days ago. They also assume that fundamental values remain constant over short horizons - i.e., between $t-k$ and today (date $t$ ). In other words, $v_{t}^{i}=v_{t-k}^{i}$. These two assumptions imply $p_{t-k}^{i}=v_{t}^{i}$. Stock prices today are simply their past prices adjusted by the intervening returns: $p_{t}^{i}=p_{t-k}^{i}+\sum_{\tau=k-1}^{0} r_{t-\tau}^{i}$. Researchers are then able to substitute the following into the numerator of Equation (1):

$$
\sum_{\tau=k-1}^{0} r_{t-\tau}^{i} \simeq p_{t}^{i}-v_{t}^{i}
$$

Equation (2) serves as the basis for many return/reversal sorting studies. Stocks are sorted on the basis of past returns. High-return stocks are likely to be trading above fundamental values and low-return stocks are likely to be trading below fundamental values. Indeed, portfolios of high-return stocks underperform portfolios of low-return stocks over periods of two days to several months. ${ }^{11}$ Note that most studies focus on the numerator in Equation (1) and do not consider a normalization factor (such as the $\sigma_{\epsilon_{t}^{i}}$ shown in the denominator.) Not including a normalization essentially assumes all stocks' revert to their fundamental values at the same rate.

\subsection{Trading Imbalances, Inventories, and Reversals}

A second approach used in empirical studies of reversals focuses on proxies for the price deviations shown in Equation (1). Inventories are a logical choice. Microstructure models

\footnotetext{
${ }^{11}$ There is a separate line of research that uses past returns to sort stocks by expected returns. Stocks with low past returns are thought to have higher expected returns than stocks with high past returns. This phenomenon, sometimes called the "leverage effect," leads to observationally similar reversals. Specifically, researchers find highreturn stocks underperform low-return stocks over short horizons. Our double-sort results in Section 6 using both inventories and past returns provide direct evidence (which are not sensitive to excluding stocks with prices less than $\$ 5)$ that liquidity in the form of inventories is part of the explanation for short-horizon reversals.
} 
provide a clear mapping between price deviations and market maker inventory levels. When investors are selling, prices prices fall, market makers buy shares, which leaves market makers with positive inventory levels. When investors are buying, prices rise, market makers sell shares, which leaves them with negative (short) inventory levels. Researchers can also sort stocks by distance from target inventory levels: $I N V_{t}^{i}-\mu_{t}^{I N V, i}$.

As discussed in the introduction, data on inventories have not been readily available, so researchers have searched for proxies. Recent work uses trading imbalances in a manner similar to using returns as in Equation (2). First, inventories are assumed to have been at a target level $k$-days ago. In other words, $I N V_{t-k}^{i}=\mu_{t-k}^{I N V, i}$. An inventory level today is simply its past level adjusted by the intervening trades of the market maker. Under a second assumption that the market maker takes the other side of all initiated buys and sells, we can write $I N V_{t}^{i}=I N V_{t-k}^{i}+\sum_{\tau=k-1}^{0} S e l l_{t-\tau}^{i}-B u y_{t-\tau}^{i}$. Third, the target inventory level is assumed not to change over short horizons: $\mu_{t}^{I N V, i}=\mu_{t-k}^{I N V, i}$. These allows researchers to construct the following:

$$
\sum_{\tau=k-1}^{0} S e l l_{t-\tau}^{i}-B u y_{t-\tau}^{i} \simeq I N V_{t}^{i}-\mu_{t}^{I N V, i} .
$$

Market makers may control their inventories differently across stocks. Thus, the speed at which prices reverse may depend on inventory control policies. Inventory control policies depend on trading activity, stock volume, and market maker participation rates. This implies that imbalance measures of inventory can be standardized. Chordia and Subrahmanyam (2004) standardize by dividing by trading volume. If we assume that the expected imbalance is zero, the specialist takes on all buy/sell imbalances, and the standard deviation of specialists inventory is proportional to trading volume, then the standardized imbalance and inventory measures can we written as:

$$
\frac{\sum_{\tau=k-1}^{0} S e l l_{t-\tau}^{i}-B u y_{t-\tau}^{i}}{\sum_{\tau=k-1}^{0} B u y_{t-\tau}^{i}+S e l l_{t-\tau}^{i}} \simeq \frac{I N V_{t}^{i}-\mu_{t}^{I N V, i}}{\sigma_{I N V_{t}^{i}}}
$$

If all trades are initiated by investors with a market maker, then the order imbalance correctly measure changes in inventory. However, the NYSE's up-tick rule requires short sellers to use limit orders, causing these trades - which are as much as $25 \%$ of trading volume (Diether, Lee, and Warner (2005)) and correlated with future price changes (Boehmer, Jones, and Zhang (2005)) - to be classified as buys. In addition, if inventories were not at their target 
level as of date $t$ - $k$, then inventory changes measure inventory levels with some error. Given the rate at which inventories mean revert in our data (Figure 5) and the up-tick short-sale rule, order imbalances are likely to be a noisy and potentially biased measure of specialist inventory levels. However, order imbalances have the advantage that they may capture market making activity and inventory by traders other than the specialists.

\section{Future Returns and Inventories, Past Returns, and Order Im- balances}

Lehmann (1990), Jegadeesh (1990), and others study return reversals by sorting stocks based on past returns. ${ }^{12}$ While these papers focus on the implications of reversals for market efficiency, if liquidity suppliers are not perfectly competitive or have limited risk bearing capacity, liquidity supplier inventories may predict return reversals. In this section we investigate the ability of inventories to predict reversals over and above any predictability contained in past returns. Our methodology employs conditional double-sorts in which we first sort stocks into quintiles based on one variable. Within each quintile, we then sort stocks into quintiles based on a second variable. The result is a set of twenty-five, evenly-populated bins. $^{13}$

In Table 5, Panel A we first sort based on past returns and next sort by our standardized inventory measure $\left(z^{I N V}\right)$. We then measure returns over the following day $(t+1)$. The double sort results confirm the existence of inventory-based reversals as seen in the single sort results. Conditional on yesterday's return, high (long) inventories today predict high returns tomorrow: average returns are between 6.02 and 13.49 basis points per day. Low (short) inventories today predict low returns tomorrow as returns are between 1.62 and -3.86 basis points per day. Note, the average return of the CRSP value-weighted index is 4.71 basis points per day over the same period. The difference between high and low inventory bins conditional on return quintile ranges between 7.85 and 16.33 basis points.

\footnotetext{
${ }^{12}$ For evidence on short-run reversal strategies and their profitability see Conrad, Hameed, and Niden (1994), Ball, Kolthari, and Wasley (1995), Cooper (1999), Avramov, Chordia, and Goyal (2005), and others. See Avramov, Chordia, and Goyal (2005) for evidence that return reversals are due to illiquidity, which provides indirect evidence to support the hypothesis that return reversals are due to inventory effects.

${ }^{13}$ Inventories and returns are negatively correlated as can be seen in Table 2 and Figure 2. A conditional double sorting methodology ensures evenly-populated bins while independent sorts would leave certain bins-e.g., lowinventory/low-return and high-inventory/high-return - sparsely populated.
} 
[ Insert Table 5 Here ]

In Table 5, Panel B we first sort based on standardized inventories and we then sort by past returns. It is clear that returns do not predict reversals at a one-day horizon. Within each inventory quintile, high return stocks outperform low return firms by 1.90 to 5.35 basis points per day (calculated as the difference between stock returns in the high-return column and stocks in the low-return column).

Table 5 highlights the returns of the portfolio one expects to exhibit the most largest reversals. The difference between the high-inventory/low-return portfolio and the lowinventory/high-return portfolio is 15.43 basis points per day in Panel A and 12.78 basis points per day in Panel B. When we compare with the 10.25 basis points from the singlesorting (Table 3, Panel C), we conclude that at the 1-day horizon, inventories predict reversals over and above past returns (Table 5, Panel A), but returns do not predict reversals over and above inventories (Table 5, Panel B).

\subsection{Short-Term Continuation (Momentum)}

Table 5 shows that specialists appear to have information about which stocks experience short-term return continuations (momentum) and which stocks experience short-term return reversals. In both Panel A and Panel B, specialists with high inventories in stocks that have high returns today see the stocks go up an additional 13.49 and 13.24 basis points the following day. Specialists with low (short) inventories in stocks that have low returns today see the stocks return 0.75 and -3.47 basis points the following day. Thus, a portfolio long high-inventory/high-return stocks and short low-inventory/low-return stocks has returns of 12.74 and 16.70 basis points the following day. However, there is no evidence that specialists inventory level predict returns at longer (weekly) horizons.

\subsection{Inventories, Past Returns, and Returns at 1, 5, and 10 Days}

Table 6 reports results of return/inventory sorts at a 1-day, 1-week, and 2-week horizons. We define one week ahead $(w+1)$ to be trading days $t+1$ through $t+5$ and two weeks ahead $(w+2)$ as trading days $t+6$ through $t+10$. To avoid difficulties in calculating statistical significance in samples with overlapping observations - Valkanov (2003) - for the 1- and 2 -week returns we only calculate variables every 5 trading days and calculate returns for 
week 1 and week 2 separately. For these nonoverlapping periods, in Panel A we carry out single-sorts based on both inventories and past returns. The 1-day results based on sorting stocks into quintiles based on current inventory levels come directly from Table 3, Panel C. Inventories and current returns predict reversals of 32.99 and 58.78 basis points, respectively, over a 5-day period. ${ }^{14}$ For the second five day period, the average reversals are 8.10 and 25.15 basis points based on inventories and return respectively. All returns in Table 6 are from zero-cost/long-short portfolios. Both inventories and past returns predict economically and statistically significant reversals at 5-day horizons. The results for the second week are smaller and of less statistical significance, especially for inventories.

\section{[ Insert Table 6 Here ]}

To determine whether inventories and returns are complementary or overlapping when predicting returns, Table 6 summarizes conditional double-sort results. Panel B first sorts by returns and finds that, conditional on past returns, portfolios of high-inventory stocks outperform portfolios of low-inventory stocks by 7.85 to 16.33 basis points at a 1-day horizon (as in Table 5, Panel A). High-inventory stocks outperform low-inventory stocks by 4.34 to 26.98 basis points over the first five days. Notice that stocks with more extreme prior returns exhibit larger reversals based on their inventories. The 1-day and 5-day results show that inventory effects exist in addition to reversals based only on past returns. However, return reversals based upon inventories are weak in the second week. We also report returns of the zero-cost portfolio that one expects to exhibit the largest reversal. At a 5-day horizon, the high-inventory/low-return bin outperforms the low-inventory/high-return bin by an average of 75.94 basis points. This value is about 50 percent larger than the 5 -day return-only reversal.

Table 6, Panel C summarizes the second set of conditional double-sort results. We first sort by inventories and show that portfolios of high-return stocks do not outperform portfolios of low-return stocks at a 1-day horizon. In fact, short-term continuations (negative reversals as in Table 5, Panel B) of -1.90 to -5.35 basis points exist for all inventory quintiles. Lowreturn stocks outperform high-return stocks by 33.42 to 76.65 basis points over the following five days. The 5-day reversals are almost twice as large for the more extreme inventory quintiles, suggesting that part of the unconditional return reversals of 58.78 basis points in Panel $\mathrm{A}$ is due to inventory effects. At a 5-day horizon, the high-inventory/low-return

\footnotetext{
${ }^{14}$ Our return-only reversals are smaller than those found by Lehmann (1990) and Avramov, Chordia and Goyal (2005) due to the use of value-weighted returns.
} 
portfolio outperforms the low-inventory/high-return portfolio by an average of 105.22 basis points. This value is almost double the 5-day reversal from returns alone and more than triple the 5-day reversal from inventories alone. Reversals based on returns are significant in the second week, but do not depend on inventory levels/quintiles.

We began this section by asking if inventories can predict reversals over and above past returns. At a 1-day horizon, returns have no forecasting power, but inventories predict return reversals. Inventories also contain information about 1-day price continuations (momentum). At a 5-day horizon, conditioning on inventories (after sorting on returns) increases the ability to predict reversals by 29\% (75.94 basis points versus 58.78 basis points.) Conditioning on returns (after sorting on inventories) increases the ability to predict reversal by $218 \%$ (105.22 basis points versus 32.99 basis points). Inventories have little ability to predict reversals more than one week ahead, especially after controlling for past returns. Overall the results suggest that inventories induce reversals, but that inventories do not fully explain reversals. It could be that specialist inventories are an incomplete measure of market-wide liquidity supplier inventories or that reversals are also due reversions in beliefs (overreaction). Finally, the fact that inventories predict reversals beyond past returns is consistent with Avramov, Chordia and Goyal's (2005) results that return reversals are related to liquidity.

\subsection{Inventories, Order Imbalances, and Returns at 1, 5, and 10 Days}

To attempt to capture market-wide liquidity supplier inventories (via liquidity demand) we calculate order imbalances from transaction data (TAQ). We follow the standard trade signing approach of Lee and Ready (1991) by using quotes from 5 seconds ago for data up through 1998. After 1998, we use contemporaneous quotes to sign trades - see Bessembinder (2003). We calculate all imbalance measures using only NYSE trades and quotes. As expected the NYSE up-tick rule for short sales results in order imbalances being positive on average - a result consistent with Chordia, Roll, and Subrahmanyam (2002), Chordia and Subrahmanyam (2004), and Chordia, Roll, and Subrahmanyam (2005). ${ }^{15}$

Panel A of Table 7 presents the cross-sectional average of each stocks' daily time-series contemporaneous correlation between order imbalances, returns, inventories, and changes in inventories (similar to Panel B of Table 2.) We present two measures of order imbalances: "\$OIB" which is the daily buyer-initiated dollar volume minus the seller-initiated

\footnotetext{
${ }^{15}$ Diether, Lee, and Warner (2005) how Regulation SHO's relaxation in 2005 of the up-tick rule largely eliminates the positive bias in NYSE order imbalances that are signed using the Lee and Ready (1991) algorithm.
} 
dollar volume and "OIB" which is the net dollar imbalance divided by the day's or week's dollar trading volume. As in Chordia, Roll, and Subrahmanyam (2002) and Chordia and Subrahmanyam (2004), imbalances are positively correlated with contemporaneous returns. The scaled/normalized order imbalance measure, $O I B$, is more highly correlated with contemporaneous returns and inventories. For this reason and because we do not want the order imbalance ranking to be heavily determined by stock size, we use the normalized order imbalance throughout the paper. In general, results using $\$ O I B$ are qualitatively similar.

Consistent with the discussion in Section 5.3, order imbalances are negatively correlated with the level of, and changes in, inventory. However, the correlation between $O I B_{t}$ and $I N V_{t}$ is only -0.17 , suggesting that specialist inventories are not highly correlated with inventories of other market makers or that the measure of order imbalance is noisy due to difficulties in signing order flow using only trades and quotes (discussed above).

\section{[ Insert Table 7 Here ]}

Panel B of Table 7 presents the cross-sectional average of each stock's weekly time-series contemporaneous correlation between order imbalances, returns, inventories, and changes in inventories. For the weekly measures we calculate weekly returns and order imbalances over the prior 5 trading days. Weekly inventory is simply the closing inventory on the final day of the 5-day week, although using only one inventory data point per week potentially reduces the power of the inventory measure. The correlation of $O I B_{t}$ with the other variables is similar at daily and weekly horizons. The weekly correlation between returns and inventories is also similar to the daily correlations in Panel B of Table 2.

In Panel A of Table 8 we first sort based on past order imbalances and next sort by standardized inventories. We then measure returns over the following day $(t+1)$. The positive correlation between $O I B_{t}$ and returns suggests that the double sorts on order imbalances and inventories may be similar to the double sorts on inventories and returns (Table 5). In Panel $\mathrm{B}$ we reverse the sort order. We first sort by inventories and then on order imbalances. As with returns, order imbalances offer little evidence of predicting reversals one day ahead. ${ }^{16}$

As with returns, the portfolios of high- $O I B /$ high-inventory stocks and low- $O I B /$ low-inventory

\footnotetext{
${ }^{16}$ Due to the positive autocorrelation in order imbalances, in time series regressions Chordia and Subrahmanyam (2004) show that today's order imbalances for a stock is positively correlated with the next day's return for that stock. If the next day's order imbalance is included in the regression as well, then today's order imbalance is negatively related to the next day's return.
} 
stocks exhibit continuations: 6.87 and 9.78 basis points for order imbalances versus 12.74 and 16.70 basis points for returns. These continuation are smaller than those from the double sorts using returns. Unlike returns, double sorts using order imbalances show no increase in one-day reversals beyond the 10.25 basis points available from inventory single-sorts. In fact, when sorting on inventories first, the reversal portfolio of low- $O I B /$ high-inventory stocks and high-OIB/low-inventory stocks shows a reversal of only 4.10 basis points. The lack of reversal evidence at a one-day horizon from order imbalances may be due to informed traders splitting their trades across days so imbalances help forecast continuations, but not reversals.

[ Insert Table 8 Here ]

Table 9 reports single and double sort results using order imbalances. Panel A contains single-sorts based on both inventories and order imbalances. The single-sort results using current inventory levels matches Panel A of Table 6. The single sort results based on order imbalances do not predict reversals one day ahead (as in Table 8), but do predict reversals of 32.03 basis points over the next week. ${ }^{17}$ Order imbalances also predict reversals in the second week, but the statistical significance is marginal.

[ Insert Table 9 Here ]

To analyze common and complementary predictability based on inventories and order imbalances, Table 9 summarizes conditional double-sort results. Panel B first sorts by order imbalances and finds that, conditional on order imbalances, portfolios of high-inventory stocks outperform portfolios of low-inventory stocks by 7.07 to 13.75 basis points at a 1-day horizon (as in Table 8, Panel A). High-inventory stocks outperform low-inventory stocks by 8.58 to 44.65 basis points over the first five days. At a 5-day horizon, the high-inventory/low-OIB portfolio outperforms the low-inventory/high-OIB portfolio by 55.37 basis points, which is about two thirds larger than the 5-day reversal based on sorting by inventories or order imbalances alone. Inventories continue to have little forecasting power in the second week.

Table 9, Panel C reverses the order of sorting from that in Panel B. As in Table 8, conditional on inventories, order imbalances predict continuations over the next day. Over the next week,

\footnotetext{
${ }^{17}$ See Subrahmanyam (2005) for a more detailed examination of the impact of order imbalances at longer (monthly) horizons. Given that order flow and returns are public information, it is surprising that these can predict future returns. However, Avramov, Chordia and Goyal (2005) show that because the predictable returns are concentrated in illiquid stocks, trading costs are likely larger than the trading profits from the return predictability.
} 
conditional on inventories, order imbalance predict reversals of 8.34 to 27.03 basis points. The forecasting power of both imbalances and inventories is weak for returns two weeks ahead. The portfolio that one expects to exhibit the largest reversals, high-inventory/low$O I B$ stocks minus the low-inventory/high- $O I B$ stocks, returns 49.77 basis points over the next week, which is roughly $50 \%$ larger than the reversal based on inventories or order imbalances alone.

The double sorts of inventories and order imbalances suggest that both measures predict reversals over the next week. There appears to be some commonality in the predictive power of inventories and order imbalances in that double sort returns are less than the sum of single sort sort returns. However, the returns on the double-sort reversal portfolio are at least $50 \%$ higher than the single-sort reversals, suggesting that the inventories and order imbalances also complement each other. ${ }^{18}$

\subsection{Inventories, Order Imbalances, and Returns}

The prior section demonstrates that inventories, past returns, and order imbalances all predict future returns, although at different horizons and with different levels of significance. To test all three factors together in a regression framework and account for contemporaneous correlation in returns across stocks we run Fama and MacBeth (1973) cross sectional regressions and use the time series properties of the estimated coefficients to calculate standard errors. To keep the Fama-MacBeth regressions consistent with our value-weighted sorts, we use weighted least-squares where the weights are proportional to market capitalization the previous day.

Table 10 summarizes the cross-sectional Fama-MacBeth regressions for returns one day ahead (Panel A), one week ahead (Panel B), and the second week ahead (Panel C). For each horizon we run four regressions, one with each factor individually and one with all three factors together. With few exceptions, the results in Table 10 are consistent with what the non-parametric sorting procedure found in Tables 5, 6, 8, and 9.

[ Insert Table 10 Here ]

Panel A of Table 10 shows that inventories predict the next days return and the t-statistic

\footnotetext{
${ }^{18}$ See Chordia and Subrahmanyam (2004) and Subrahmanyam (2005) for analysis of the commonality and complementarity of returns and order imbalances.
} 
of 9.80 is similar to the single sort t-statistic of 9.34 in Table 6. In Regressions A2 today's returns predict small, but not statistically significant, continuations the next day, as in Panel A of Table 6. However, in Regression A3 order imbalances predict a return reversal with a t-statistic of 2.83. This differs from the not statistically significant result in the single sort on order imbalances in Panel A of Table 9.

Regression A4 includes all three variables in the regression. The coefficient on inventories continues to be negative with both the magnitude of the coefficient and its t-statistic increasing over the univariate regression. Returns now predict continuations. The coefficient on $O I B_{t}$ remains negative, but falls and becomes less statistically significant with a t-statistic of 2.39. These results suggest that inventories and order imbalances predict reversals the following day, while, conditional on these, returns continue in the same direction.

Panel B of Table 10 repeats the regressions in Panel A on a weekly basis, where, as in the single sorts, the weeks are non overlapping. At a one-week horizon, all three variables predict reversals individually with t-statistics between 5 and 7 . The t-statistics are close to those found in the weekly single sorts in Tables 6 and 9 . When the three variables are all included in Regression B4, the coefficients all remain the same sign, but decrease in magnitude and statistical significance. The coefficient and t-statistic on returns fall the least and the coefficient and t-statistic on order imbalances fall the most. The weekly results suggest that inventories, returns, and order imbalances each predict reversals. Conditional on the other variables, returns have the most significant predictive power and order imbalances have the least power.

Panel C repeats the weekly analysis in Panel B with a two-week horizon (returns from trading days $t+6$ through $t+10)$. As with the single sorts all three variable predicts reversals individually with returns being statistically significant, order imbalances being marginally significant, and inventories not being statistically significant. When all three variables are combined in Regression C4 inventories and order imbalances become effectively zero and only returns remain significant.

\section{Conclusion}

Liquidity and limits to arbitrage arguments regarding asset prices rely on the idea that certain market participants accommodate buying or selling pressure. These liquidity suppliers/arbitrageurs will only bear the risk of holding undiversified positions if they are compen- 
sated by favorable subsequent price movements. Thus, when inventories are large, liquidity suppliers have taken on risk, and prices should subsequently reverse. Using a unique 11-year sample of NYSE specialist inventories, this paper tests and confirms the underlying causal mechanism - liquidity supplier inventory - linking liquidity and stock return reversals.

Consistent with specialists acting as dealers and temporarily accommodating buying and selling pressure, specialist inventories are negatively correlated with contemporaneous returns at both at the aggregate market level and individual stock level. We find that specialists are compensated for the inventory risk by return reversals. While past returns also predict reversals, inventories contain orthogonal information and a portfolio long high-inventory/lowreturn stocks and short low-inventory/high-return stocks earns more than portfolios using only inventories or only past returns. Order imbalances calculated from signing trades (as buyer-initiated or seller-initiated using trades and quotes) also predict reversals and are complementary to inventories and past returns. Finally, specialist inventories are able to predict continuations over a one-day horizon.

Substantial work remains to be done in order to understand the dynamics of market maker inventories and stock prices. While papers on liquidity and asset prices have discovered important relationships between them, e.g., Amihud and Mendelson (1986), Pastor and Stambaugh (2003), Acharya and Pedersen (2005), and others, a better understanding of their dynamics may help guide future research. In particular, exactly why price impact and other transaction costs differ across stocks and differ in their sensitivity to market liquidity has yet to be fully addressed. By showing the market maker inventories impact prices at the daily and weekly horizons this paper helps formalize a causal link between liquidity and stock prices.

A possible step in better understanding liquidity varies across stocks is to study market maker risk management. Inventory risk management may occur on a stock-by-stock basis, across stocks traded an individual market maker, or across stocks traded by a firm employing multiple market makers. The organizational structure of specialists on the NYSE can help to disentangle where risk management takes place because an individual specialist has exclusive responsibility for a group of stocks - referred to as a "panel". Given the structure of specialist firms and our results linking inventories to past and future returns, the manner in which specialists manages risk may have cross-stock pricing implications, i.e., Do specialists hedge positions in one stock with other stocks in their panel? Do firms hedge individual stock positions with other stocks?, etc. The length and breadth of our data can help estimate inventory management via mean reversion rates both cross sectionally and over time. 
A second line of research is to deepen our understanding of the commonality of liquidity (Chordia, Roll, and Subrahmanyam (2000), Coughenour and Saad (2004), and others) and its relationship to commonality in stock returns (Hasbrouck and Seppi (2001)). In particular, if inventories drive the liquidity commonality then the pricing effects should be stronger when inventories are moving together at the panel level and firm level. For example, a large sell order in a given stock typically increases the specialist's holdings in that stock and limits his ability/desire to buy more of the stock. The large sell order may also limit his ability to purchase other stocks. Thus, the price effects of a temporary buy-sell imbalance might be transmitted to another stock, even when the two stocks are not subject to the same (original) buy-sell imbalance. Additionally, stocks which are more likely to have buy-sell imbalances at exactly the same time as other stocks suffer large buy-sell imbalances could lead to the liquidity risk factor studied by Pastor and Stambaugh (2003).

A third line of research is to investigate layers of liquidity provision in the stock market. Given the specialists' unique position in the trading process, they represent the first level of liquidity provision. However, if their risk bearing capacity is limited, the specialists' holdings are an imperfect measure of available market-wide liquidity. Other investors such as hedge funds and investment banks are willing to provide liquidity and take on undiversified positions, provided they are sufficiently compensated via future price movements. The specialist inventories predict returns over a one- to two-week horizon even though the specialists tend upwind their positions quickly (Figure 5). To reduce their inventories the specialists may be trading with secondary and tertiary layers of liquidity providers. An empirical strategy to identify liquidity provision by other investors/arbitraguers would provide insight into how long markets take to fully share risk after liquidity shocks. Understanding the implications of a market not being able to share risk immediately or frictionlessly will deepen our knowledge of how long and to what magnitude asset prices might deviate from fundamental values. 


\section{References}

[1] Acharya, Viral, and Lasse Pedersen (2005), Asset pricing with liquidity risk, Journal of Financial Economics 77, 375410.

[2] Amihud, Yakov, and Haim Mendelson, 1980, Dealership market: Market making with inventory, Journal of Financial Economics 8, 31-54.

[3] Amihud, Yakov, and Haim Mendelson, 1986, Asset pricing and the bid-ask spread, Journal of Financial Economics 17, 223249.

[4] Andrade, Sandro, Mark Seasholes, and Charles Chang, 2005, Predictable reversals, cross-stock effects, and the limits of arbitrage, working paper, University of California, Berkeley.

[5] Avramov, Doron, Tarun Chordia, and Amit Goyal, 2005, Liquidity and autocorrelation of individual stock returns, Journal of Finance, forthcoming.

[6] Ball, Ray, S. P. Kothari, and Jay Shanken, 1995, Problems in measuring portfolio performance: An application to contrarian investment strategies, Journal of Financial Economics 38, 79-107.

[7] Barber, Brad, Terrance Odean, and Ning Zhu, 2005, Do noise traders move markets? Working paper, University of California.

[8] Bessembinder, Hendrik, 2003, Issues in assessing trade execution costs, Journal of Financial Markets, Journal of Financial Markets 6, 233-257.

[9] Boehmer, Ekkehart, Charles Jones, and Xiaoyan Zhang, 2005, Which shorts are informed? working paper, Columbia University.

[10] Campbell, John, Sanford Grossman, and Jiang Wang, 1993, Trading volume and serial correlation in stocks returns, Quarterly Journal of Economics 108, 905-939.

[11] Campbell, John, Tarun Ramadorai, and Tuomo Vuolteenaho, 2005, Caught on Tape: Institutional order flow and stock returns, working paper, Columbia University.

[12] Cao, Henry, Martin Evans, and Richard Lyons, 2006, Inventory Information, Journal of Business 79, 325-364.

[13] Chordia, Tarun, Richard Roll, and Avanidhar Subrahmanyam, 2000, Commonality in Liquidity, Journal of Financial Economics, 56, 3-28. 
[14] Chordia, Tarun, Richard Roll, and Avanidhar Subrahmanyam, 2002, Order imbalance, liquidity and market returns, Journal of Financial Economics 65, 111-130.

[15] Chordia, Tarun, Richard Roll, and Avanidhar Subrahmanyam, 2005, Evidence on the speed of convergence to market efficiency, Journal of Financial Economics, forthcoming.

[16] Chordia, Tarun, Richard Roll, and Avanidhar Subrahmanyam, 2005, Liquidity and market efficiency, Working paper, Emory University.

[17] Chordia, Tarun, and Avanidhar Subrahmanyam, 2004, Order imbalance and individual stock returns, Journal of Financial Economics 72, 485-518.

[18] Conrad, Jennifer, Allaudeen Hameed and Cathy Niden, 1994, Volume and autocovariances in short-horizon individual security returns, Journal of Finance 49, 1305-1329.

[19] Cooper, Michael, 1999, Filter rules based on price and volume in individual security overreaction, Review of Financial Studies 12, 901-935.

[20] Coughenour, Jay, and Lawrence Harris, 2004, Specialist profits and the minimum price increment, Working paper, University of Southern California.

[21] Coughenour, Jay, and Mohsen Saad, 2004, Common market makers and commonality in liquidity, Journal of Financial Economics 73, 37-69.

[22] Coval, Joshua, and Erik Stafford, 2005, Asset fire sales (and purchases) in equity markets, Working paper, Harvard University.

[23] Diether, Karl, Kuan Lee, and Ingrid Werner, 2005, It's SHO time! Short-sale price-test and market quality, working paper, Ohio State University.

[24] Fama, Eugene, and James MacBeth, 1973, Risk, return, and equilibrium, Journal of Political Economy 33, 3-56.

[25] Garleanu, Nicolae, Lasse Pedersen, and Allen Poteshman, 2005, Demand-based option pricing, Working paper, New York University.

[26] Grossman, Sanford, and Merton Miller, 1988, Liquidity and market structure, Journal of Finance 43, 617-633.

[27] Hansch, Oliver, Narayan Naik, and S. Viswanathan, 1998, Do inventories matter in dealership markets? Evidence from the London Stock Exchange, Journal of Finance $53,1623-1655$. 
[28] Hasbrouck, Joel, and Duane Seppi, 2001, Common factors in prices, order flows, and liquidity, Journal of Financial Economics 59, 383-411.

[29] Hasbrouck, Joel, and George Sofianos, 1993, The trades of market-makers: An analysis of NYSE specialists, Journal of Finance 48, 1565-1594.

[30] Ho, Thomas, and Hans Stoll, 1981, Optimal dealer pricing under transactions and return uncertainty, Journal of Financial Economics 9, 47-73.

[31] Lee, Charles, and Mark Ready, 1991, Inferring trade direction from intraday data, Journal of Finance 46, 733-747.

[32] Lehmann, Bruce, 1990, Fads, martingales, and market efficiency, Quarterly Journal of Economics 105, 1-28.

[33] Llorente, Guillermo, Roni Michaely, Gideon Saar, and Jiang Wang, 2002, Dynamic volume-return relation of individual stocks, Review of Financial Studies 15, 1005-1047.

[34] Lyons, Richard, 2001, The Microstructure Approach to Exchange Rates, MIT Press: Cambridge, MA.

[35] Jagadeesh, Narasimhan, 1990, Evidence of predictable behavior of security returns, Journal of Finance 45, 881-898.

[36] Kraus, Alan, and Hans Stoll, 1972, Price impacts of block trading on the New York Stock Exchange, Journal of Finance 27, 569-588.

[37] Madhavan, Ananth, and Seymour Smidt, 1993, An analysis of daily changes in specialist inventories and quotations, Journal of Finance 48, 1595-1628.

[38] Madhavan, Ananth, and George Sofianos, 1998, An empirical analysis of NYSE specialist trading, Journal of Financial Economics 48, 189-210.

[39] Mann, Steven, and Steven Manaster, 1996, Life in the pits: Competitive market making and inventory control, Review of Financial Studies 9, 953-975.

[40] Naik, Narayan, and Pradeep Yadav, 2003, Do dealer firms manage inventory on a stockby-stock or a portfolio basis? Journal of Financial Economics 69, 325-353.

[41] Pastor, Lubos, and Robert Stambaugh, 2003, Liquidity risk and expected stock returns, Journal of Political Economy 111, 642-685. 
[42] Reiss, Peter, and Ingrid Werner, 1998, Does risk sharing motivate inter-dealer trading? Journal of Finance 53, 1657-1704.

[43] Roll, Richard, 1984, A simple implicit measure of the effective bid-ask spread in an efficient market, Journal of Finance 39, 1127-1139.

[44] Spiegel, Matthew and Avanidhar Subrahmanyam, 1995, On intraday risk premia, Journal of Finance 50, 319-339.

[45] Subrahmanyam, Avanidhar, 2005, Lagged order flows and returns: A longer-term perspective, Working paper, UCLA.

[46] Valkanov, Rossen, 2003, Long-Horizon regressions: Theoretical results and applications, Journal of Financial Economics 68, 201-232. 
Table 1

\section{Descriptive Statistics of Inventory Positions}

This table gives descriptive statistics of NYSE specialists' inventory positions. Panel A gives time-series statistics for the aggregate market inventory as shown in Figure 1. Aggregate market inventory levels are calculated as the sum, across all stocks in our sample, of each specialists' inventory at the close of each trading day. Panel B gives cross-sectional statistics at the individual stock level. Inventories are measured at the end of each day. The sample period starts 03-Jan-1994 and ends 31-Dec-2004.

Panel A: Time-Series Measures of Aggregate Market Inventory

\begin{tabular}{rccc} 
& $I N V_{t}^{m k t}$ & $\Delta I N V_{t}^{m k t}$ & $\left|\Delta I N V_{t}^{m k t}\right|$ \\
& $(\$$ million $)$ & (\$ million) & (\$ million) \\
\hline Average & 196.16 & -0.03 & 76.59 \\
Stdev & 136.78 & 106.96 & 74.65 \\
\# Days & 2,731 & 2,730 & 2,730
\end{tabular}

Panel B: Daily Cross-Sectional Measures of Inventory and Changes of Inventory

\begin{tabular}{|c|c|c|c|c|c|c|}
\hline & $\begin{array}{l}I N V_{t} \\
(\$ 000)\end{array}$ & $\begin{array}{l}\left|I N V_{t}\right| \\
(\$ 000)\end{array}$ & $\frac{I N V_{t}}{V_{o l} l_{t}^{M A}}$ & $\begin{array}{l}\Delta I N V_{t} \\
(\$ 000)\end{array}$ & $\begin{array}{r}\left|\Delta I N V_{t}\right| \\
(\$ 000)\end{array}$ & $\frac{\Delta I N V_{t}}{V o l_{t}^{M A}}$ \\
\hline Average & 119.08 & 305.66 & 0.24 & 0.07 & 239.91 & -0.00 \\
\hline $1^{\text {st }}$-tile & $-1,478.58$ & 0.37 & -1.13 & $-1,647.70$ & 0.11 & -0.51 \\
\hline $5^{\text {th }}$-tile & -459.26 & 4.60 & -0.20 & -570.81 & 1.91 & -0.17 \\
\hline $10^{\text {th }}$-tile & -227.64 & 11.15 & -0.08 & -307.46 & 5.25 & -0.09 \\
\hline $25^{\text {th }}$-tile & -39.00 & 37.72 & -0.01 & -82.37 & 21.88 & -0.03 \\
\hline $50^{\text {th }}$-tile & 41.18 & 113.30 & 0.01 & 0.18 & 80.21 & 0.00 \\
\hline $75^{\text {th }}$-tile & 185.54 & 294.76 & 0.09 & 80.70 & 237.75 & 0.03 \\
\hline $90^{\text {th }}$-tile & 490.10 & 672.10 & 0.40 & 302.22 & 564.64 & 0.09 \\
\hline $95^{\text {th }}$-tile & 858.40 & $1,112.66$ & 0.91 & 560.74 & 921.32 & 0.16 \\
\hline $99^{\text {th }}$-tile & 2,429.61 & $2,929.24$ & 4.61 & $1,548.25$ & $2,256.27$ & 0.46 \\
\hline
\end{tabular}


Table 2

Correlation of Variables

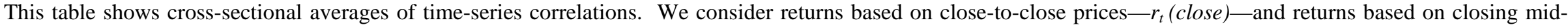

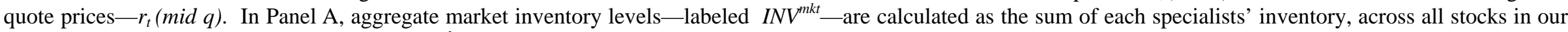

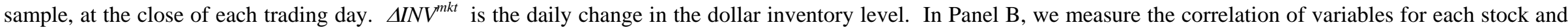

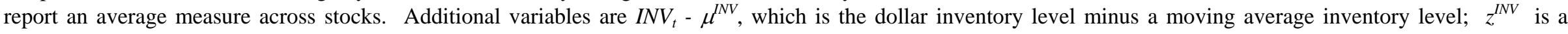

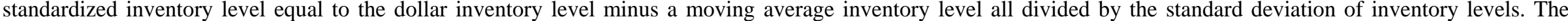

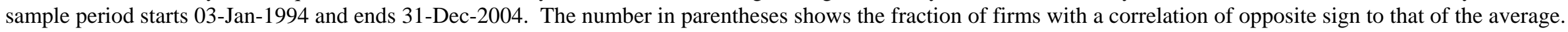

Panel A: Aggregate Market

\begin{tabular}{c|cccc} 
& $r_{t}^{m k t}($ close $)$ & $r_{t}^{m k t}(\operatorname{mid} q)$ & $I N V_{t}^{m k t}$ & $\Delta I N V_{t}^{m k t}$ \\
\hline$r_{t}^{m k t}($ close $)$ & 1.00 & & \\
$r_{t}^{m k t}($ mid q) & 1.00 & 1.00 & \\
$I N V_{t}^{m k t}$ & -0.57 & -0.57 & 1.00 & \\
$\Delta I N V_{t}^{m k t}$ & -0.71 & -0.71 & 0.39
\end{tabular}

Panel B: Individual Stocks

\begin{tabular}{|c|c|c|c|c|c|c|}
\hline & $r_{t}$ (close) & $r_{t}(\operatorname{mid} q)$ & $I N V_{t}$ & $I N V_{t}-\mu^{I N V}$ & $Z_{t}^{I N V}$ & $\Delta I N V_{t}$ \\
\hline$r_{t}($ close $)$ & 1.00 & & & & & \\
\hline$r_{t}(\operatorname{mid} q)$ & $\begin{array}{c}0.96 \\
(0.00)\end{array}$ & 1.00 & & & & \\
\hline$I N V_{t}$ & $\begin{array}{l}-0.23 \\
(0.02)\end{array}$ & $\begin{array}{l}-0.24 \\
(0.02)\end{array}$ & 1.00 & & & \\
\hline$I N V_{t}-\mu^{I N V}$ & $\begin{array}{l}-0.23 \\
(0.03)\end{array}$ & $\begin{array}{l}-0.23 \\
(0.02)\end{array}$ & $\begin{array}{c}0.86 \\
(0.00)\end{array}$ & 1.00 & & \\
\hline$Z_{t}^{I N V}$ & $\begin{array}{l}-0.24 \\
(0.03)\end{array}$ & $\begin{array}{l}-0.25 \\
(0.03)\end{array}$ & $\begin{array}{c}0.76 \\
(0.00)\end{array}$ & $\begin{array}{c}0.86 \\
(0.00)\end{array}$ & 1.00 & \\
\hline$\Delta I N V_{t}$ & $\begin{array}{l}-0.31 \\
(0.03)\end{array}$ & $\begin{array}{l}-0.31 \\
(0.03)\end{array}$ & $\begin{array}{c}0.38 \\
(0.00)\end{array}$ & $\begin{array}{c}0.39 \\
(0.00)\end{array}$ & $\begin{array}{c}0.37 \\
(0.00)\end{array}$ & 1.00 \\
\hline
\end{tabular}


Table 3

Sort Results

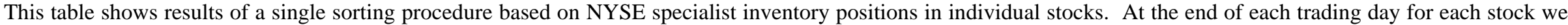

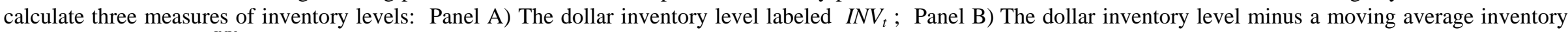

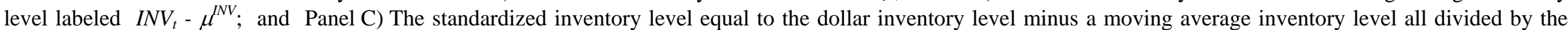

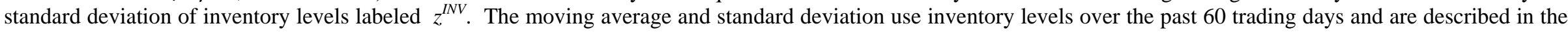

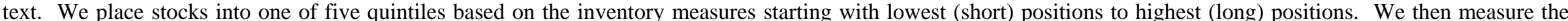

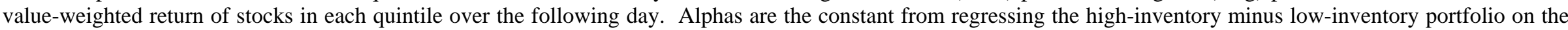

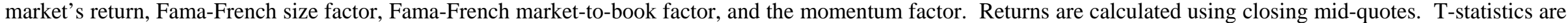
based on Newey-West standard errors that are robust to heteroscedasticity and autocorrelation. The sample period starts 03-Jan-1994 and ends 31-Dec-2004.

Panel A: Sort by $I N V_{t}$

\begin{tabular}{|c|c|c|c|c|c|c|c|c|c|}
\hline $\begin{array}{c}\text { Sort } \\
\text { Quintile }\end{array}$ & $\begin{array}{c}I N V_{t} \\
(\$ 000)\end{array}$ & $I N V_{t}-\mu^{I N V}$ & $z^{I N V}$ & $\begin{array}{l}\text { Turnover } \\
\text { (bp) }\end{array}$ & $\begin{array}{c}\text { Return } \\
\text { Stdev (\%) }\end{array}$ & $\begin{array}{c}\text { MktCap } \\
\text { (\$ bn) }\end{array}$ & $\begin{array}{c}r_{t+1} \\
(\mathbf{b p})\end{array}$ & $\begin{array}{c}\text { H-L (bp) } \\
\text { (T-stat) }\end{array}$ & $\begin{array}{c}\text { Alpha } \\
\text { (T-stat) }\end{array}$ \\
\hline Lo (-) 1 & -441.14 & -473.28 & -1.31 & 45.22 & 2.18 & 7.66 & 0.15 & 8.47 & 8.66 \\
\hline 2 & -212.84 & -66.86 & -0.52 & 39.87 & 2.81 & 2.26 & 2.54 & (9.67) & (10.09) \\
\hline 3 & 42.97 & -13.88 & 0.04 & 38.22 & 2.78 & 1.94 & 4.47 & & \\
\hline 4 & 148.81 & 61.64 & 0.55 & 41.81 & 2.44 & 3.00 & 7.55 & & \\
\hline $\mathrm{Hi}(+) 5$ & 863.61 & 490.13 & 1.22 & 49.37 & 2.25 & 9.78 & 8.62 & & \\
\hline
\end{tabular}

Panel B: Sort by INV - $\mu^{I N V}$

\begin{tabular}{|c|c|c|c|c|c|c|c|c|c|}
\hline $\begin{array}{c}\text { Sort } \\
\text { Quintile }\end{array}$ & $\begin{array}{c}I N V_{t} \\
(\$ 000)\end{array}$ & $I N V_{t}-\mu^{I N V}$ & $z^{I N V}$ & $\begin{array}{l}\text { Turnover } \\
\text { (bp) }\end{array}$ & $\begin{array}{c}\text { Return } \\
\text { Stdev (\%) }\end{array}$ & $\begin{array}{c}\text { MktCap } \\
\text { (\$ bn) }\end{array}$ & $\begin{array}{c}r_{t+1} \\
(\mathbf{b p})\end{array}$ & $\begin{array}{c}\text { H-L (bp) } \\
\text { (T-stat) }\end{array}$ & $\begin{array}{c}\text { Alpha } \\
\text { (T-stat) }\end{array}$ \\
\hline Lo (-) 1 & -301.01 & -603.51 & -1.42 & 49.02 & 2.25 & 9.16 & 0.92 & 7.70 & 7.18 \\
\hline 2 & -0.94 & -92.15 & -0.73 & 41.48 & 2.52 & 2.57 & 2.94 & (9.23) & $(8.76)$ \\
\hline 3 & 43.57 & -6.07 & -0.09 & 36.59 & 2.99 & 1.58 & 5.54 & & \\
\hline 4 & 134.49 & 81.27 & 0.71 & 39.58 & 2.50 & 2.52 & 7.23 & & \\
\hline $\mathrm{Hi} \mathrm{(+)} 5$ & 717.16 & 617.74 & 1.51 & 47.82 & 2.20 & 8.81 & 8.62 & & \\
\hline
\end{tabular}

Panel C: Sort by $z^{I N V}$

\begin{tabular}{|c|c|c|c|c|c|c|c|c|c|}
\hline $\begin{array}{c}\text { Sort } \\
\text { Quintile }\end{array}$ & $\begin{array}{c}I N V_{t} \\
(\$ 000)\end{array}$ & $I N V_{t}-\mu^{I N V}$ & $\mathrm{z}^{I N V}$ & $\begin{array}{l}\text { Turnover } \\
\text { (bp) }\end{array}$ & $\begin{array}{c}\text { Return } \\
\text { Stdev (\%) }\end{array}$ & $\begin{array}{c}\text { MktCap } \\
\text { (\$ bn) }\end{array}$ & $\begin{array}{l}r_{t+1} \\
(\mathbf{b p})\end{array}$ & $\begin{array}{c}\text { H-L (bp) } \\
\text { (T-stat) }\end{array}$ & $\begin{array}{c}\text { Alpha } \\
\text { (T-stat) }\end{array}$ \\
\hline Lo (-) 1 & -286.06 & -482.97 & -1.74 & 39.75 & 2.50 & 4.17 & -0.60 & 10.25 & 9.96 \\
\hline 2 & -28.23 & -182.56 & -0.54 & 44.97 & 2.58 & 4.89 & 2.06 & (9.34) & (9.18) \\
\hline 3 & -20.29 & -20.29 & -0.05 & 45.73 & 2.50 & 5.84 & 4.99 & & \\
\hline 4 & 230.20 & 171.50 & 0.47 & 44.00 & 2.43 & 5.46 & 7.51 & & \\
\hline $\mathrm{Hi} \mathrm{(+)} 5$ & 512.02 & 512.02 & 1.84 & 40.04 & 2.45 & 4.28 & 9.65 & & \\
\hline
\end{tabular}


Table 4

\section{Risk-Adjusted Returns}

Returns of zero-cost sort portfolios called $r^{H-L}$ in basis points are regressed on the market's return and other factors' returns. The zero cost portfolio is formed by sorting on NYSE specialists' current inventory positions. We use a standardized measure $\left(z^{I N V}\right)$ described in the text. We measure closing mid-quote to mid-quote returns of the zerocost portfolio on the $k^{\text {th }}$ day following the sorting day. The size factor (SMB), the market-to-book factor (HML), and the momentum factor (UMD) are from Ken French's website. Returns are calculated using closing mid-quotes. T-statistics are based on Newey-West standard errors that are robust to heteroscedasticity and autocorrelation. The sample period starts 03-Jan-1994 and ends 31-Dec-2004.

$$
r_{t+k}^{H-L}=\alpha+\beta^{M K T}\left(r_{t+k}^{m}-r_{t+k}^{f}\right)+\beta^{S M B} r_{t+k}^{S M B}+\beta^{H M L} r_{t+k}^{H M L}+\beta^{U M D} r_{t+k}^{U M D}+\varepsilon_{t+k}
$$

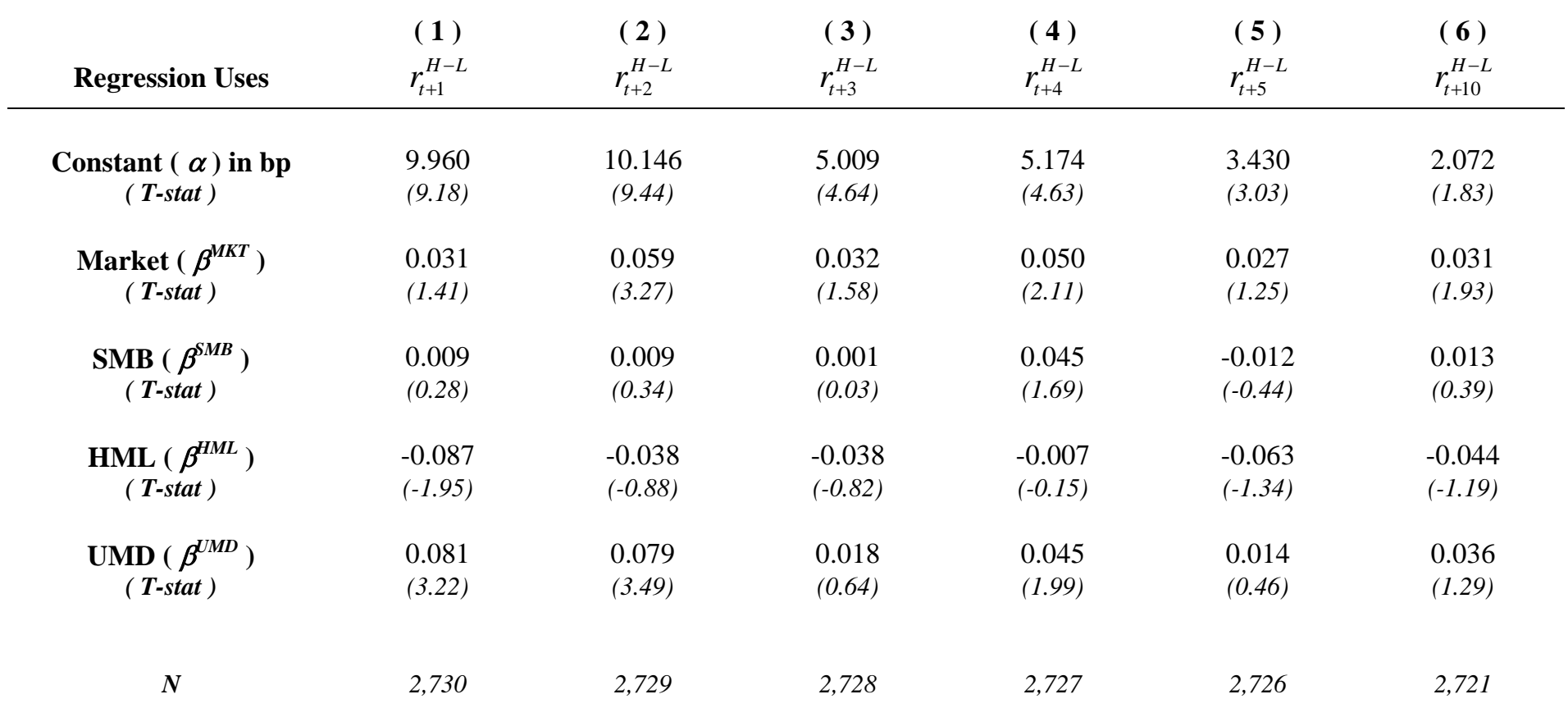


Table 5

Double Sort : Current Inventories and Current Returns as Predictors of Returns on Day $\mathbf{t}+1$

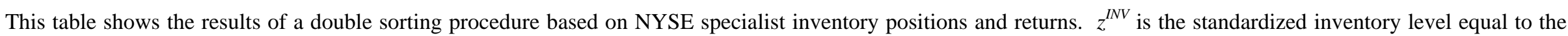

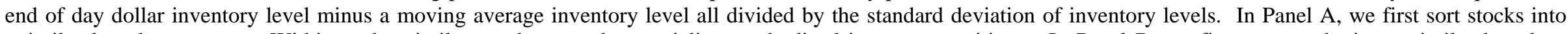

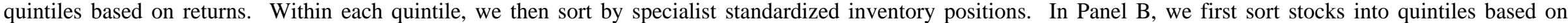

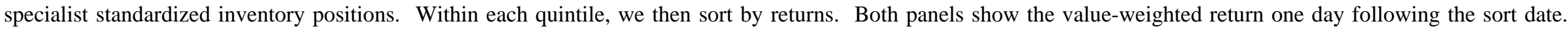

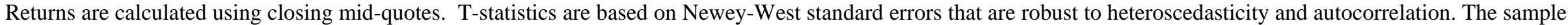
period starts 03-Jan-1994 and ends 31-Dec-2004.

Panel A: $1^{\text {st }}$ Sort Stock Returns; $2^{\text {nd }}$ Sort Specialist Inventory Shown Returns on Day $t+1$ (bp)

\begin{tabular}{|c|c|c|c|c|c|c|}
\hline \multicolumn{4}{|c|}{$\operatorname{Lo}(-) z^{I N V}$} & & & \multirow{2}{*}{$\begin{array}{c}\mathrm{Hi}(+) z^{I N V} \\
5\end{array}$} \\
\hline & & 1 & 2 & 3 & 4 & \\
\hline \multirow[t]{4}{*}{ Hi (+) } & $r_{t}$ & -2.84 & 4.65 & 5.33 & 7.52 & 13.49 \\
\hline & 4 & 1.62 & 2.73 & 4.89 & 7.53 & 9.46 \\
\hline & 3 & -2.28 & 1.62 & 6.03 & 7.43 & 8.51 \\
\hline & 2 & -3.86 & -0.39 & 4.78 & 4.85 & 6.02 \\
\hline Lo (-) r & $r_{t}$ & 0.75 & 2.01 & 5.30 & 9.34 & 12.59 \\
\hline
\end{tabular}

\begin{tabular}{cc} 
Reversal & Continuation \\
Portfolio & Portfolio \\
Long: & Long: \\
Lo $\boldsymbol{r}_{t} \&$ Hi $z^{I N V}$ & Hi $\boldsymbol{r}_{t}$ \& Hi $z^{I N V}$ \\
Short: & Short: \\
Hi $\boldsymbol{r}_{t}$ \&o $z^{I N V}$ & Lo $\boldsymbol{r}_{t}$ \& Lo $z^{I N V}$ \\
\hline & \\
15.43 & 12.74 \\
$(6.32)$ & $(5.04)$ \\
&
\end{tabular}

Panel B: $1^{\text {st }}$ Sort Specialist Inventory; $2^{\text {nd }}$ Sort Stock Returns Shown Returns on Day $\mathbf{t}+1$ (bp)

\begin{tabular}{r|ccccc} 
& Hi (+) $\boldsymbol{r}_{\boldsymbol{t}}$ & & & \multicolumn{2}{c}{ Lo (-) $\boldsymbol{r}_{\boldsymbol{t}}$} \\
\hline $\mathbf{L o ~ ( - )} \mathbf{z}^{I N V}$ & $\mathbf{5}$ & $\mathbf{4}$ & $\mathbf{3}$ & $\mathbf{2}$ & -3.47 \\
$\mathbf{2}$ & -1.56 & 0.37 & 1.56 & -2.95 & -0.12 \\
$\mathbf{3}$ & 5.22 & 4.06 & 2.53 & -1.23 & 4.46 \\
$\mathbf{4}$ & 9.91 & 5.64 & 4.51 & 2.83 & 5.73
\end{tabular}

\begin{tabular}{cc}
$\begin{array}{c}\text { Reversal } \\
\text { Portfolio }\end{array}$ & $\begin{array}{c}\text { Continuation } \\
\text { Portfolio }\end{array}$ \\
Long: & Long: \\
Hi $z^{I N V}$ \& Lo $r_{t}$ & Hi $z^{I N V} \&$ Hi $r_{t}$ \\
Short: & Short: \\
Lo $z^{I N V}$ \& Hi $r_{t}$ & Lo $z^{I N V}$ \&o $r_{t}$ \\
\hline & \\
12.78 & 16.70 \\
$(4.35)$ & $(7.33)$
\end{tabular}


Table 6

Sorting Results Based on Inventories and Returns at 1-Day, 1-Week, and 2-Week Horizons

This table shows the results of sorting procedures at 1-day, 5-day, and 10-day horizons. Panel A shows the results of two singlesorts based on standardized inventory levels and returns. $z^{I N V}$ is the standardized inventory level equal to the end of day or week dollar inventory level minus a moving average inventory level all divided by the standard deviation of inventory levels. Panel B shows double-sort results. We first sort stocks into quintiles based on returns. Within each quintile, we then sort by standardized inventory levels. Panel C also shows double-sort results where we first sort stocks into quintiles based on specialist standardized inventory positions. Within each quintile, we then sort by returns. One week head returns $\left(r_{w+1}\right)$ are returns for trading days $t+1$ through $t+5$ and 2-week ahead returns $\left(r_{w+2}\right)$ are for trading days $t+6$ through $t+10$. Returns are calculated using closing midquotes. T-statistics are based on Newey-West standard errors that are robust to heteroscedasticity and autocorrelation. The sample period starts 03-Jan-1994 and ends 31-Dec-2004.

\section{Panel A: Single Sorts}

\begin{tabular}{cccc} 
Sort Portfolio & $r_{t+1}$ & $r_{w+1}$ & $r_{w+2}$ \\
\hline Hi $z^{I N V}-$ Lo $z^{I N V}$ & 10.25 & 32.99 & 8.10 \\
(T-stat) & $(9.34)$ & $(6.68)$ & $(1.49)$ \\
Lo $r_{t}-$ Hi $r_{t}$ & 0.42 & 58.78 & 25.15 \\
(T-stat) & $(0.23)$ & $(6.32)$ & $(2.33)$
\end{tabular}

Panel B: Double Sort on Returns then Inventories

\begin{tabular}{crccc}
$\mathbf{1}^{\text {st }}$ Sort Variable & $\mathbf{2}^{\text {nd }}$ Sort Portfolio & $r_{t+1}$ & $r_{w+1}$ & $r_{w+2}$ \\
\hline Hi $r_{t}$ & Hi $z^{I N V}-$ Lo $z^{I N V}$ & 16.33 & 12.33 & -1.94 \\
4 & Hi $z^{I N V}-$ Lo $z^{I N V}$ & 7.85 & 4.34 & 10.02 \\
3 & Hi $z^{I N V}-$ Lo $z^{I N V}$ & 10.80 & 11.62 & 4.04 \\
2 & Hi $z^{I N V}-$ Lo $z^{I N V}$ & 9.88 & 20.09 & -6.02 \\
Lo $r_{t}$ & Hi $z^{I N V}-$ Lo $z^{I N V}$ & 11.84 & 26.98 & -5.50 \\
Hi $z^{I N V} /$ Lo $r_{t}-$ Lo $z^{I N V} /$ Hi $r_{t}$ Reversal & 15.43 & 75.94 & 18.25 \\
& (T-stat) & $(6.32)$ & $(6.99)$ & $(1.36)$
\end{tabular}

Panel C: Double Sort on Inventories then Returns

\begin{tabular}{crccc}
$\mathbf{1}^{\text {st }}$ Sort Variable & $\mathbf{2}^{\text {nd }}$ Sort Portfolio & $r_{t+1}$ & $r_{w+1}$ & $r_{w+2}$ \\
\hline Lo $z^{I N V}$ & Lo $r_{t}-$ Hi $r_{t}$ & -1.90 & 67.20 & 23.00 \\
2 & Lo $r_{t}-$ Hi $r_{t}$ & -5.35 & 33.42 & 25.03 \\
3 & Lo $r_{t}-$ Hi $r_{t}$ & -2.45 & 38.25 & 23.45 \\
4 & Lo $r_{t}-$ Hi $r_{t}$ & -3.72 & 54.18 & 26.73 \\
Hi $z^{I N V}$ & Lo $r_{t}-$ Hi $r_{t}$ & -2.04 & 76.65 & 20.05 \\
Hi $z^{I N V} /$ Lo $r_{t}-$ Lo $z^{I N V} /$ Hi $r_{t}$ Reversal & 12.78 & 105.22 & 14.13 \\
& (T-stat) & $(4.35)$ & $(7.73)$ & $(0.88)$
\end{tabular}


Table 7

Correlation of Order Imbalances

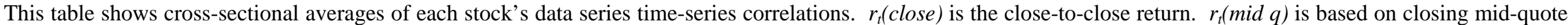

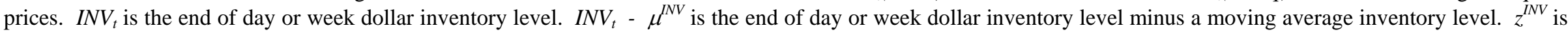

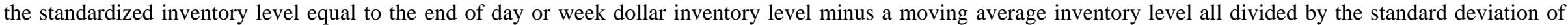

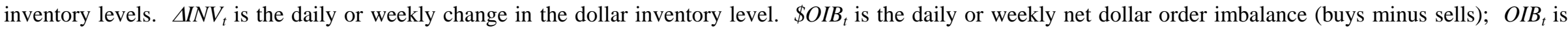

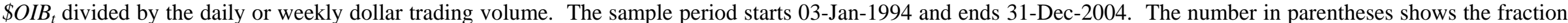
of firms with a correlation of opposite sign to that of the average.

Panel A: Individual Stocks-Daily

\begin{tabular}{|c|c|c|c|c|c|c|c|c|}
\hline & $r_{t}($ close $)$ & $r_{t}(\operatorname{mid} q)$ & $I N V_{t}$ & $I N V_{t}-\mu^{I N V}$ & $z_{t}^{I N V}$ & $\Delta I N V_{t}$ & $\$ O I B_{t}$ & $O I B_{t}$ \\
\hline$\$ O I B_{t}$ & $\begin{array}{c}0.20 \\
(0.07)\end{array}$ & $\begin{array}{c}0.20 \\
(0.08)\end{array}$ & $\begin{array}{l}-0.15 \\
(0.06)\end{array}$ & $\begin{array}{l}-0.14 \\
(0.05)\end{array}$ & $\begin{array}{l}-0.14 \\
(0.05)\end{array}$ & $\begin{array}{l}-0.17 \\
(0.05)\end{array}$ & 1.00 & \\
\hline$O I B_{t}$ & $\begin{array}{c}0.29 \\
(0.00)\end{array}$ & $\begin{array}{c}0.29 \\
(0.00)\end{array}$ & $\begin{array}{l}-0.17 \\
(0.04)\end{array}$ & $\begin{array}{l}-0.16 \\
(0.02)\end{array}$ & $\begin{array}{l}-0.17 \\
(0.02)\end{array}$ & $\begin{array}{l}-0.19 \\
(0.01)\end{array}$ & $\begin{array}{c}0.57 \\
(0.00)\end{array}$ & 1.00 \\
\hline
\end{tabular}

Panel B: Individual Stocks—Weekly

\begin{tabular}{|c|c|c|c|c|c|c|c|c|}
\hline & $r_{w}($ close $)$ & $r_{w}(\operatorname{mid} q)$ & $I N V_{w}$ & $I N V_{w}-\mu^{I N V}$ & $z_{w}^{I N V}$ & $\Delta I N V_{w}$ & $\$ O I B_{w}$ & $O I B_{w}$ \\
\hline$r_{w}($ close $)$ & 1.00 & & & & & & & \\
\hline$r_{w}(\operatorname{mid} q)$ & $\begin{array}{c}0.99 \\
(0.00)\end{array}$ & 1.00 & & & & & & \\
\hline$I N V_{w}$ & $\begin{array}{r}-0.25 \\
(0.04)\end{array}$ & $\begin{array}{l}-0.25 \\
(0.04)\end{array}$ & 1.00 & & & & & \\
\hline$I N V_{w}-\mu^{I N V}$ & $\begin{array}{l}-0.24 \\
(0.05)\end{array}$ & $\begin{array}{c}-0.24 \\
(0.05)\end{array}$ & $\begin{array}{c}0.86 \\
(0.00)\end{array}$ & 1.00 & & & & \\
\hline$Z_{w}^{I N V}$ & $\begin{array}{l}-0.25 \\
(0.06)\end{array}$ & $\begin{array}{l}-0.25 \\
(0.06)\end{array}$ & $\begin{array}{c}0.76 \\
(0.00)\end{array}$ & $\begin{array}{c}0.86 \\
(0.00)\end{array}$ & 1.00 & & & \\
\hline$\Delta I N V_{w}$ & $\begin{array}{l}-0.24 \\
(0.06)\end{array}$ & $\begin{array}{l}-0.24 \\
(0.05)\end{array}$ & $\begin{array}{c}0.54 \\
(0.00)\end{array}$ & $\begin{array}{c}0.56 \\
(0.00)\end{array}$ & $\begin{array}{c}0.52 \\
(0.00)\end{array}$ & 1.00 & & \\
\hline$\$ O I B_{w}$ & $\begin{array}{c}0.21 \\
(0.10)\end{array}$ & $\begin{array}{c}0.21 \\
(0.10)\end{array}$ & $\begin{array}{l}-0.15 \\
(0.12)\end{array}$ & $\begin{array}{l}-0.13 \\
(0.12)\end{array}$ & $\begin{array}{l}-0.12 \\
(0.11)\end{array}$ & $\begin{array}{l}-0.11 \\
(0.13)\end{array}$ & 1.00 & \\
\hline$O I B_{w}$ & $\begin{array}{c}0.29 \\
(0.01)\end{array}$ & $\begin{array}{c}0.29 \\
(0.01)\end{array}$ & $\begin{array}{l}-0.17 \\
(0.06)\end{array}$ & $\begin{array}{l}-0.16 \\
(0.05)\end{array}$ & $\begin{array}{l}-0.17 \\
(0.05)\end{array}$ & $\begin{array}{l}-0.14 \\
(0.06)\end{array}$ & $\begin{array}{c}0.66 \\
(0.00)\end{array}$ & 1.00 \\
\hline
\end{tabular}


Table 8

Double Sort : Current Inventories and Net Order Imbalances as Predictors of Returns on Day $\mathbf{t}+1$

This table shows the results of a double sorting procedure based on NYSE specialist inventory positions and net order imbalances. $z^{I N V}$ is the standardized inventory level equal to the end of day dollar inventory level minus a moving average inventory level all divided by the standard deviation of inventory levels. $O I B_{t}$ the daily net dollar order imbalance (buys minus sells) divided by the daily dollar trading volume. In Panel A, we first sort stocks into quintiles based on net order imbalance. Within each quintile, we then sort by specialist standardized inventory positions. In Panel B, we first sort stocks into quintiles based on specialist standardized inventory positions. Within each quintile, we then sort by net order imbalances. Both panels show the value-weighted return one-day following the sort date. Returns are calculated using closing mid-quotes. T-statistics are based on Newey-West standard errors that are robust to heteroscedasticity and autocorrelation. The sample period starts 03-Jan-1994 and ends 31-Dec-2004.

Panel A: $1^{\text {st }}$ Sort Order Imbalances; $2^{\text {nd }}$ Sort Specialist Inventory; Shown Returns on Day t+1 (bp)

\begin{tabular}{|c|c|c|c|c|c|c|c|}
\hline & $\begin{array}{c}\operatorname{Lo}(-) z^{I N} \\
1\end{array}$ & 2 & 3 & 4 & $\begin{array}{c}\mathrm{Hi}(+) z^{I N V} \\
5\end{array}$ & $\begin{array}{l}\text { Reversal } \\
\text { Portfolio }\end{array}$ & $\begin{array}{c}\text { Continuation } \\
\text { Portfolio }\end{array}$ \\
\hline $\mathrm{Hi}(+) O I B_{t}$ & -0.20 & 4.43 & 5.32 & 7.26 & 6.87 & $\begin{array}{l}\text { Long: } \\
\text { Lo OIB \& } \mathrm{Hi}^{\text {INV }}\end{array}$ & $\begin{array}{l}\text { Long: } \\
\text { Hi OIB \& } \mathrm{Hi}^{I N V}\end{array}$ \\
\hline 4 & -1.31 & 3.83 & 3.90 & 6.71 & 9.52 & $\begin{array}{c}\text { Short: } \\
\text { Hi OIB } \& \text { \& Lo z } z^{I N V} \\
\end{array}$ & $\begin{array}{c}\text { Short: } \\
\text { Lo } O I B_{t} \& \text { Lo } z^{N V}\end{array}$ \\
\hline 3 & 0.96 & 0.63 & 4.14 & 6.73 & 9.88 & \multirow{3}{*}{$\begin{array}{c}9.42 \\
(4.95)\end{array}$} & \multirow{3}{*}{$\begin{array}{c}6.87 \\
(3.09)\end{array}$} \\
\hline 2 & -2.24 & 3.96 & 6.26 & 10.53 & 11.50 & & \\
\hline Lo (-) OIB & 0.00 & 3.30 & 4.75 & 7.55 & 9.22 & & \\
\hline
\end{tabular}

Panel B: $1^{\text {st }}$ Sort Specialist Inventory; $2^{\text {nd }}$ Sort Net Order Imbalances; Shown Returns on Day t+1 (bp)

\begin{tabular}{|c|c|c|c|c|c|c|c|}
\hline & $\begin{array}{c}\mathrm{Hi}(+) O I B_{t} \\
5\end{array}$ & 4 & 3 & 2 & $\begin{array}{c}\mathrm{Lo}(-) O I B_{t} \\
1\end{array}$ & $\begin{array}{l}\text { Reversal } \\
\text { Portfolio }\end{array}$ & $\begin{array}{c}\text { Continuation } \\
\text { Portfolio }\end{array}$ \\
\hline $\operatorname{Lo}(-) z^{I N V}$ & 3.13 & -1.10 & 1.15 & -1.91 & -0.40 & $\begin{array}{c}\text { Long: } \\
\mathrm{Hi} z^{I N V} \text { \& Lo OIB } \text { OI }_{t}\end{array}$ & $\begin{array}{l}\text { Long: } \\
\mathrm{Hi} z^{\mathrm{NVV}} \text { \& } \mathrm{Hi} \mathrm{OIB}_{t}\end{array}$ \\
\hline 2 & 5.11 & 4.38 & 0.98 & 1.87 & 1.00 & 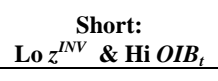 & 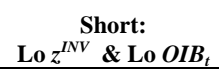 \\
\hline 3 & 7.04 & 4.90 & 3.80 & 6.51 & 3.29 & \multirow{3}{*}{$\begin{array}{l}4.10 \\
(2.22)\end{array}$} & \multirow{3}{*}{$\begin{array}{l}9.78 \\
(4.84)\end{array}$} \\
\hline 4 & 5.87 & 7.74 & 7.61 & 10.37 & 5.91 & & \\
\hline $\mathrm{Hi}(+) z^{I N V}$ & 9.38 & 9.85 & 10.50 & 10.55 & 7.23 & & \\
\hline
\end{tabular}


Table 9

Sorting Results Based on Inventories and Net Order Imbalances

Returns at 1-Day, 1-Week, and 2-Week Horizons

This table shows the results of sorting procedures at 1-day, 5-day, and 10-day horizons. Panel A shows the results of two singlesorts - the first based on standardized inventory levels and the second based on order imbalances. $z^{I N V}$ is the standardized inventory level equal to the end of day or week dollar inventory level minus a moving average inventory level all divided by the standard deviation of inventory levels. $O I B_{t}$ is the daily or weekly net dollar order imbalance (buys minus sells) divided by the daily or weekly dollar trading volume. Panel B shows double-sort results. We first sort stocks into quintiles based on order imbalances. Within each quintile, we then sort by standardized inventory levels. Panel C also shows double-sort results. We first sort stocks into quintiles based on specialist standardized inventory positions. Within each quintile, we then sort by order imbalances. One week ahead returns $\left(r_{w+1}\right)$ are returns for trading days $t+1$ through $t+5$ and 2 -week ahead returns $\left(r_{w+2}\right)$ are for trading days $t+6$ through $t+10$. Returns are calculated using closing mid-quotes. T-statistics are based on Newey-West standard errors that are robust to heteroscedasticity and autocorrelation. The sample period starts 03-Jan-1994 and ends 31-Dec-2004.

Panel A: Single Sorts

\begin{tabular}{cccc} 
Sort Portfolio & $r_{t+1}$ & $r_{w+1}$ & $r_{w+2}$ \\
\hline Hi $z^{I N V}-$ Lo $z^{I N V}$ & 10.25 & 32.99 & 8.10 \\
$\begin{array}{c}\text { (T-stat) } \\
\text { Lo OIB }- \text { Hi OIB } \\
\text { (T-stat) }\end{array}$ & $\begin{array}{c}(9.34) \\
(6.52\end{array}$ & 32.03 & $(1.49)$ \\
& $(0.48)$ & $(5.66)$ & 12.26 \\
\end{tabular}

Panel B: Double Sort on Order Imbalances then Inventories

\begin{tabular}{|c|c|c|c|c|}
\hline $1^{\text {st }}$ Sort Variable & $2^{\text {nd }}$ Sort Portfolio & $r_{t+1}$ & $r_{w+1}$ & $r_{w+2}$ \\
\hline $\mathrm{Hi} O I B_{t}$ & Hi $z^{I N V}-$ Lo $z^{I N V}$ & 7.07 & 8.58 & 0.51 \\
\hline 4 & Hi $z^{I N V}-$ Lo $z^{I N V}$ & 10.83 & 26.00 & 9.66 \\
\hline 3 & Hi $z^{I N V}-$ Lo $z^{I N V}$ & 8.91 & 22.79 & 11.68 \\
\hline 2 & Hi $z^{I N V}-$ Lo $z^{I N V}$ & 13.75 & 44.65 & -6.74 \\
\hline Lo $O I B_{t}$ & Hi $z^{I N V}-$ Lo $z^{I N V}$ & 9.22 & 25.22 & -3.06 \\
\hline \multicolumn{2}{|c|}{$\begin{array}{r}\mathrm{Hi} z^{I N V} / \mathrm{Lo} \mathrm{OIB}_{t}-\text { Lo } z^{I N V} / \mathrm{Hi} \mathrm{OIB}_{t} \text { Reversal } \\
\text { (T-stat) }\end{array}$} & $\begin{array}{c}9.42 \\
(4.95)\end{array}$ & $\begin{array}{l}55.37 \\
(6.74)\end{array}$ & $\begin{array}{c}2.42 \\
(0.42)\end{array}$ \\
\hline
\end{tabular}

Panel C: Double Sort on Inventories then Order Imbalances

\begin{tabular}{|c|c|c|c|c|}
\hline $1^{\text {st }}$ Sort Variable & $2^{\text {nd }}$ Sort Portfolio & $r_{t+1}$ & $r_{w+1}$ & $r_{w+2}$ \\
\hline Lo $z^{I N V}$ & Lo $O I B_{t}-\mathrm{Hi} O I B_{t}$ & -3.53 & 27.03 & 9.07 \\
\hline 2 & Lo $O I B_{t}-\mathrm{Hi} O I B_{t}$ & -4.12 & 23.67 & -2.65 \\
\hline 3 & Lo $O I B_{t}-\mathrm{Hi} O I B_{t}$ & -3.75 & 17.48 & 5.99 \\
\hline 4 & Lo $O I B_{t}-$ Hi $O I B_{t}$ & 0.04 & 8.34 & 13.15 \\
\hline $\mathrm{Hi} z^{I N V}$ & Lo $O I B_{t}-$ Hi $O I B_{t}$ & -2.15 & 21.43 & 15.10 \\
\hline \multicolumn{2}{|c|}{$\begin{array}{r}\text { Hi } z^{I N V} / \text { Lo } O_{1} B_{t}-\text { Lo } z^{I N V} / \text { Hi } O_{1} B_{t} \text { Reversal } \\
\text { (T-stat) }\end{array}$} & $\begin{array}{c}4.10 \\
(2.22)\end{array}$ & $\begin{array}{l}49.77 \\
(6.21)\end{array}$ & $\begin{array}{l}8.79 \\
(0.91)\end{array}$ \\
\hline
\end{tabular}


Table 10

Fama-Macbeth Regressions

This table shows the results of Fama-Macbeth regressions at 1-day, 1-week, and 2-week horizons. Each day or week we run cross-sectional regressions using weighted least squares where the weights are equal to each stock's previous day's market capitalization. Panel A uses one day ahead returns $\left(r_{t+1}\right)$; Panel B uses one week ahead returns (trading days $t+1$ through $t+5$ and labeled $r_{w+1}$ ); Panel C uses the 2 week ahead returns (trading days $t+6$ through $t+10$ and labeled $r_{w+2}$ );. Returns are calculated using closing mid-quotes. $z^{I N V}$ is the standardized inventory levels described in the text. $O I B_{t}$ is the daily or weekly net dollar order imbalance (buys minus sells) divided by the daily or weekly dollar trading volume. Reported coefficients are based on the time series averages of estimated coefficients. T-statistics are based one time series standard deviations. Newey-West standard errors are robust to heteroscedasticity and autocorrelation. The sample period starts 03-Jan-1994 and ends 31-Dec-2004.

$$
\alpha+\beta_{1}\left(z_{t}^{I N V}\right)+\beta_{2}\left(r_{t}\right)+\beta_{3}\left(O I B_{t}\right)+\varepsilon_{t}
$$

Panel A: LHS variable $r_{t+1}$ (daily)

\begin{tabular}{cccccc} 
& & Reg A1 & Reg A2 & Reg A3 & Reg A4 \\
\hline \multirow{2}{*}{ Constant } & $\alpha\left(10^{-4}\right)$ & 4.95 & 3.96 & 5.32 & 4.47 \\
& & $(2.54)$ & $(2.06)$ & $(2.75)$ & $(2.34)$ \\
$z^{I N V}$ & $\beta_{1}\left(10^{-4}\right)$ & 2.63 & & & 2.92 \\
& & $(9.80)$ & & & $(11.54)$ \\
$r_{t}$ & $\beta_{2}\left(10^{-3}\right)$ & & 1.97 & & 6.99 \\
\multirow{2}{*}{ OIB $_{t}$} & $\beta_{3}\left(10^{-4}\right)$ & & $(0.70)$ & & $(2.39)$ \\
& & & & -5.29 & -4.02 \\
& & & & $(-2.83)$ & $(-2.39)$
\end{tabular}

Panel B: LHS variable $r_{w+1}$ (weekly)

\begin{tabular}{|c|c|c|c|c|c|}
\hline & & Reg B1 & Reg B2 & Reg B3 & Reg B4 \\
\hline Constant & $\alpha\left(10^{-4}\right)$ & $\begin{array}{c}2.54 \\
(2.77)\end{array}$ & $\begin{array}{l}2.63 \\
(2.93)\end{array}$ & $\begin{array}{c}3.23 \\
(3.59)\end{array}$ & $\begin{array}{l}2.98 \\
(3.40)\end{array}$ \\
\hline$z^{I N V}$ & $\beta_{1}\left(10^{-4}\right)$ & $\begin{array}{c}6.98 \\
(5.50)\end{array}$ & & & $\begin{array}{c}4.13 \\
(3.33)\end{array}$ \\
\hline$r_{t}$ & $\beta_{2}\left(10^{-3}\right)$ & & $\begin{array}{l}-4.13 \\
(-6.69)\end{array}$ & & $\begin{array}{l}-3.67 \\
(-5.68)\end{array}$ \\
\hline$O^{\prime} B_{t}$ & $\beta_{3}\left(10^{-4}\right)$ & & & $\begin{array}{c}-9.44 \\
(-5.70)\end{array}$ & $\begin{array}{l}-3.10 \\
(-2.11)\end{array}$ \\
\hline
\end{tabular}

Panel C: LHS variable $r_{w+2}$ (weekly)

Reg C1

\begin{tabular}{|c|c|}
\hline Constant & $\alpha\left(10^{-4}\right)$ \\
\hline$z^{I N V}$ & $\beta_{1}\left(10^{-4}\right)$ \\
\hline$r_{t}$ & $\beta_{2}\left(10^{-3}\right)$ \\
\hline$O I B_{t}$ & $\beta_{3}\left(10^{-4}\right)$ \\
\hline
\end{tabular}

Reg C2

2.41

(2.71)

$-1.98$

$(-2.88)$
Reg C3

2.85

(3.10)

2.47

$-0.03$

$(-0.03)$

$-1.98$

$(-2.72)$

$-3.11$

(-1.92)
$-0.37$

$(-0.27)$ 
Figure 1

Aggregate market inventory levels in millions of dollars (LHS) and aggregate market capitalization in billions of dollars (RHS) are graphed from January 3, 1994 to December 31, 2004. Aggregate market inventory levels are calculated as the sum of each specialists' inventory, across all stocks in our sample, at the close of each trading day. Aggregate market capitalization is the sum of the market capitalization of each stock in our sample at the close of trading each day. Our sample consists of New York Stock Exchange-listed, common stocks, which can be matched with CRSP data.

— Aggregate Market Inventory (LHS, \$ million)

Market Capitalization (RHS, $\$$ billion)

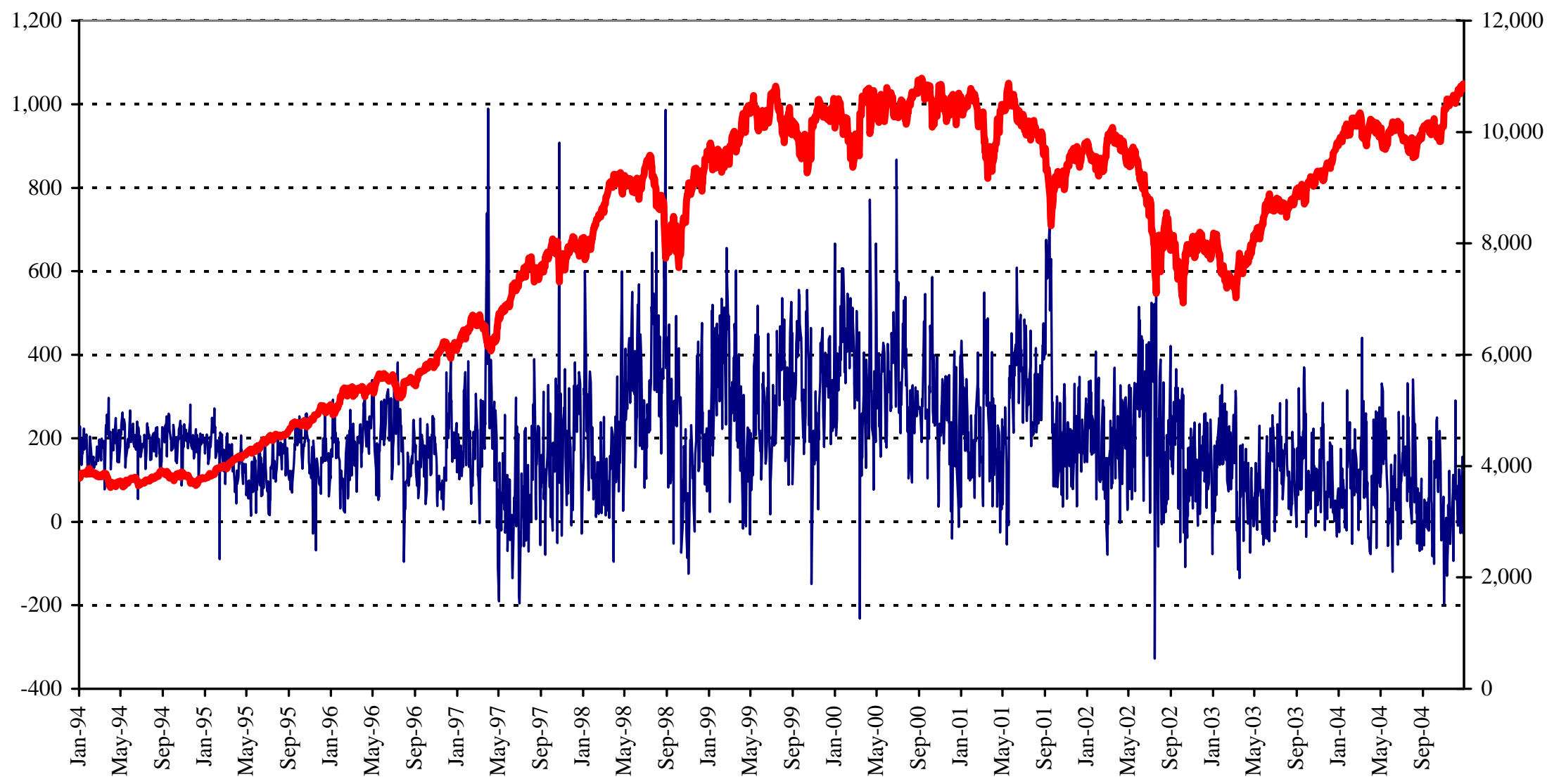




\section{Figure 2}

A scatter plot of changes in aggregate inventory (shown in millions of dollars on the Y-axis) and contemporaneous daily market returns (X-axis). Changes in aggregate inventory levels are calculated as the daily changes of each specialist's inventory summed across all stocks in our sample. Our sample consists of New York Stock Exchange-listed, common stocks, which can be matched with CRSP data. Returns are calculated using closing mid-quotes. The sample period starts 03-Jan-1994 and ends 31-Dec-2004.

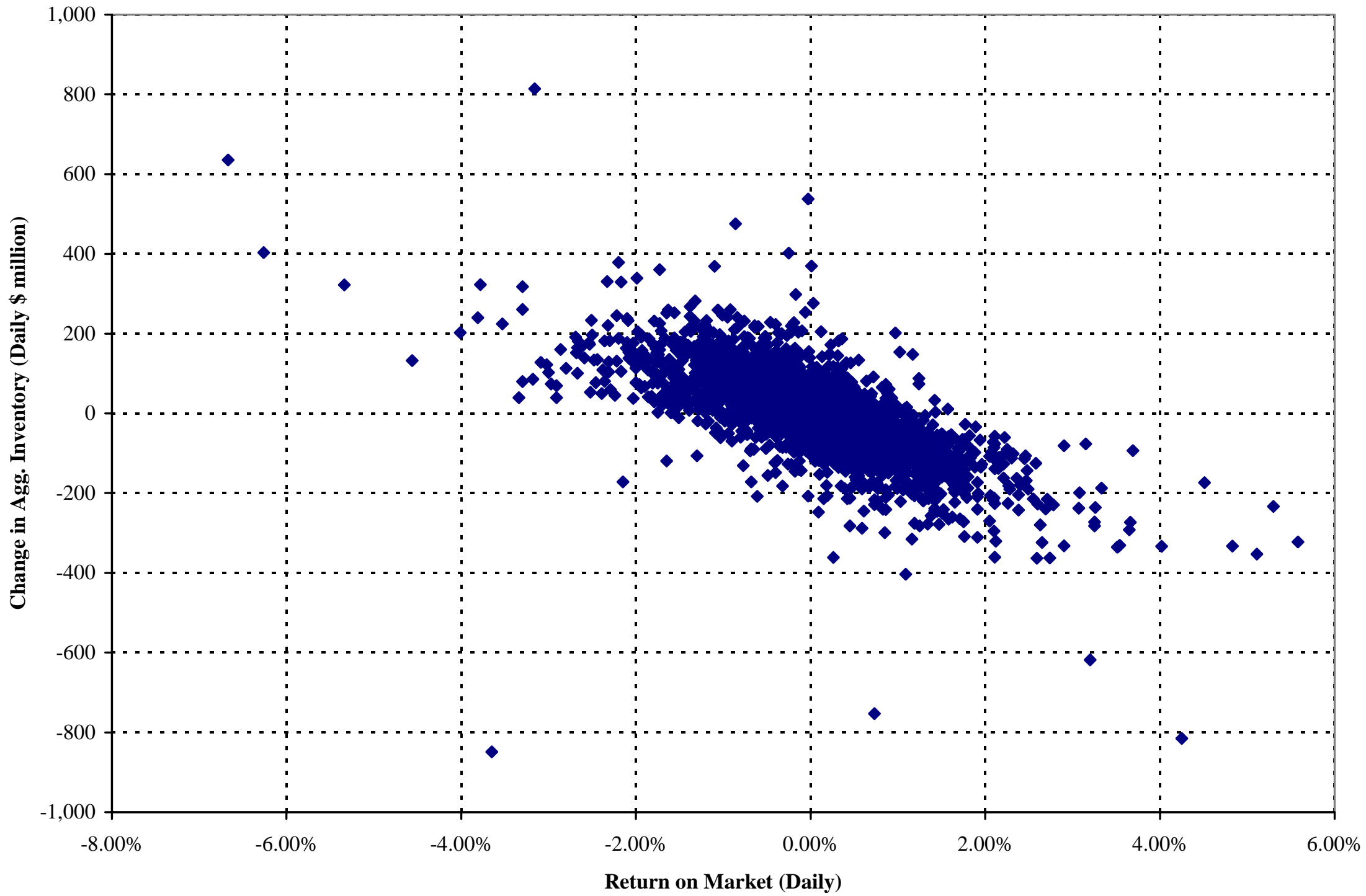




\section{Figure 3}

This figure shows the results of a single sorting procedure based on NYSE specialist inventory position in individual stocks. At the end of each trading day ( $t=0)$ for each stock we calculate the standardized inventory level $\left(\mathrm{Z}^{I N V}\right)$ equal to the dollar inventory level minus a moving average inventory level all divided by the standard deviation of inventory levels. The moving average and standard deviation measures consider inventory levels over trading days $t-11$ to $t-70$ and are described in the text. We place stocks into one of five quintiles based on the standardized inventory measures (on date $t=0$ ). Our procedure sorts stocks with quintiles from the lowest (short) positions to the highest (long) positions. We then measure the value-weighted return of stocks in each quintile over the following twelve trading days. Returns net of the market are calculated using closing mid-quotes. The sample period starts 03-Jan-1994 and ends 31-Dec-2004.

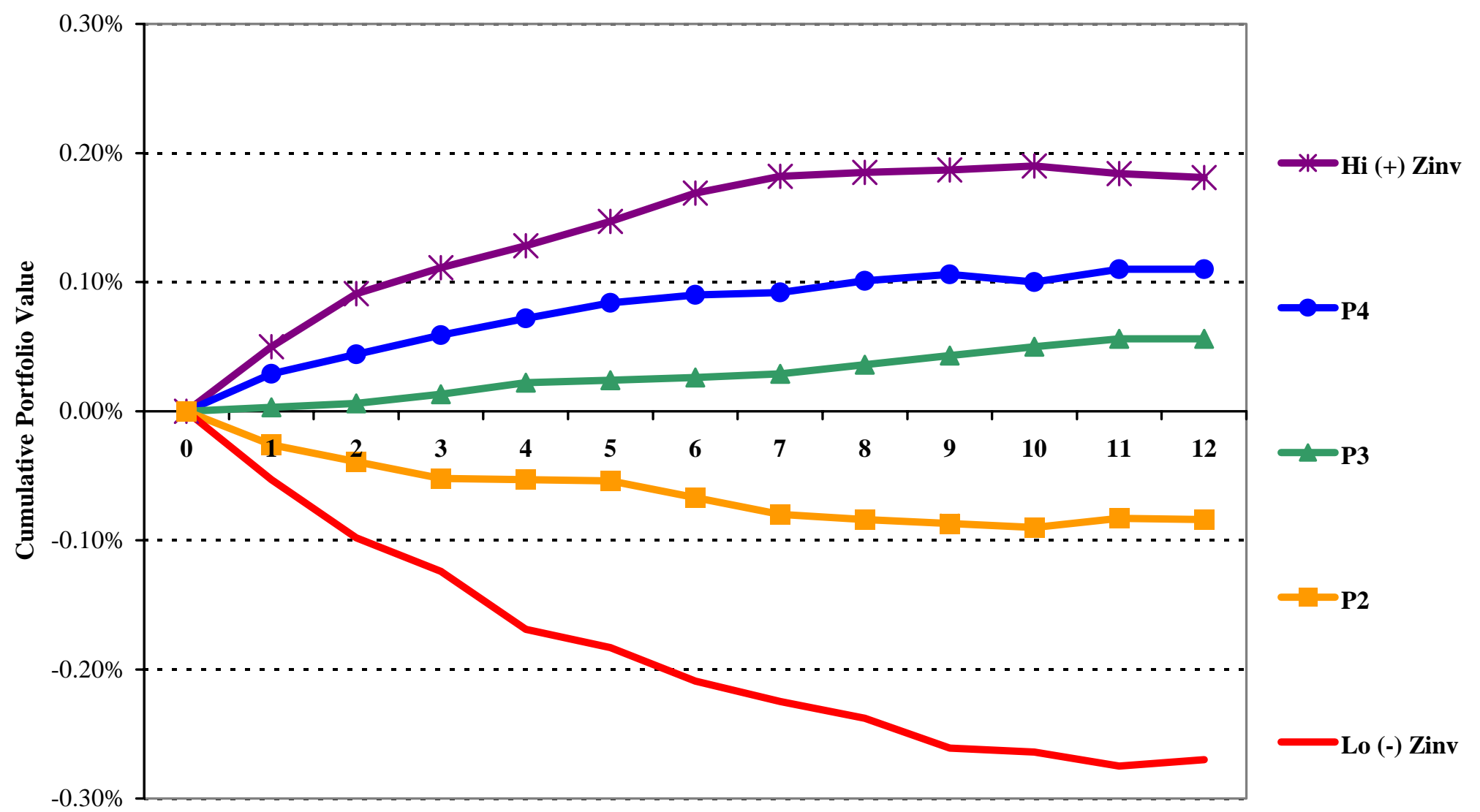

Days From Sort 


\section{Figure 4}

This figure shows the results of a single sorting procedure based on NYSE specialist inventory position in individual stocks. At the end of each trading day ( $t=0)$ for each stock, we calculate a standardized inventory level $\left(z^{I N V}\right)$ equal to the dollar inventory level minus a moving average inventory level all divided by the standard deviation of inventory levels. The moving average and standard deviation measures consider inventory levels over trading days $t-11$ to $t-70$ and are described in the text. We place stocks into one of five quintiles based on the inventory measures (at day $t=0$ ). Our procedure sorts stocks with quintiles from the lowest (short) positions to the highest (long) positions. We then measure the value-weighted return of stocks in each quintile over the five previous days and the twelve following days. Returns net of the market are calculated using closing mid-quotes. The sample period starts 03-Jan-1994 and ends 31-Dec-2004.

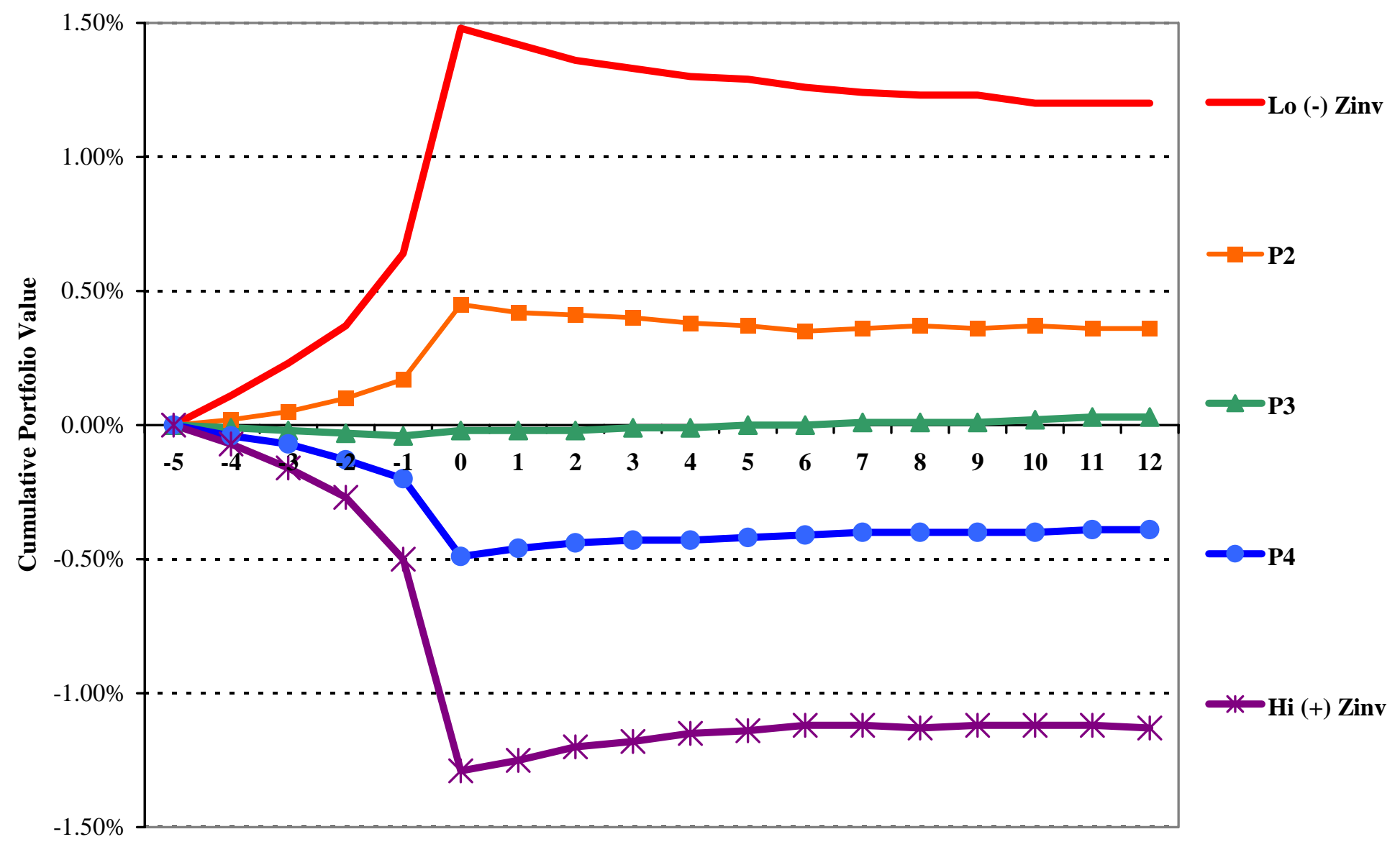

Days From Sort 


\section{Figure 5}

This figure shows the results of a single sorting procedure based on NYSE specialist inventory position in individual stocks. At the end of each trading day ( $t=0)$ for each stock, we calculate a standardized inventory level $\left(z^{I N V}\right)$ equal to the dollar inventory level minus a moving average inventory level all divided by the standard deviation of inventory levels. The moving average and standard deviation measures consider inventory levels over trading days $t-11$ to $t-70$ and are described in the text. We place stocks into one of five quintiles based on the inventory measures (at day $t=0$ ). Our procedure sorts stocks with quintiles from the lowest (short) positions to the highest (long) positions. The sample period starts 03-Jan-1994 and ends 31-Dec-2004.

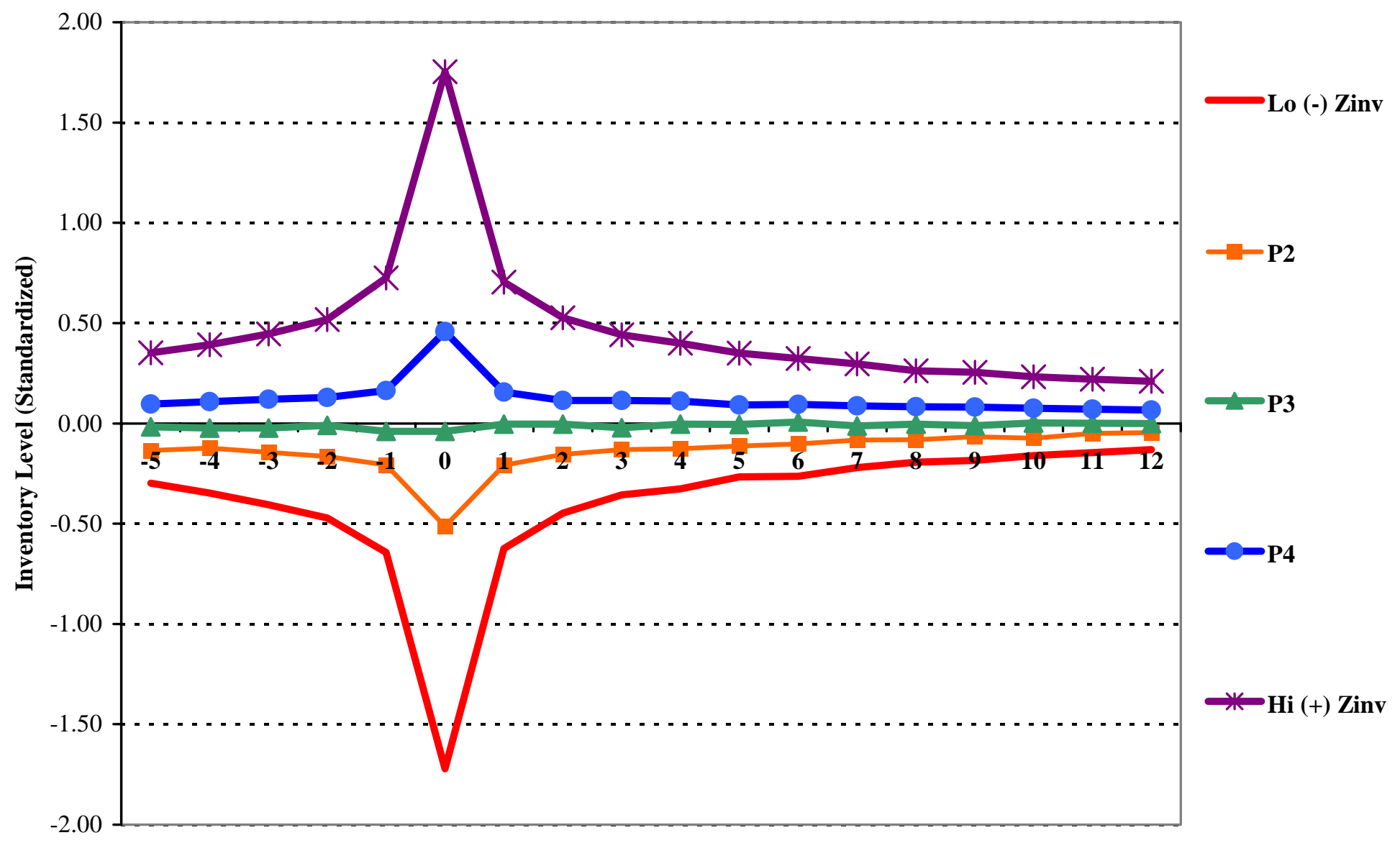

Days From Sort 